\title{
Empirically Supported Couple and Family Interventions for Marital Distress and Adult Mental Health Problems
}

\author{
Donald H. Baucom \\ University of North Carolina, Chapel Hill \\ Kim T. Mueser \\ Dartmouth University Medical School
}

\author{
Varda Shoham \\ University of Arizona
}

Anthony D. Daiuto
University of North Carolina, Chapel Hill

\author{
Timothy R. Stickle \\ University of Arizona
}

\begin{abstract}
This article evaluates the efficacy, effectiveness, and clinical significance of empirically supported couple and family interventions for treating marital distress and individual adult disorders, including anxiety disorders, depression, sexual dysfunctions, alcoholism and problem drinking, and schizophrenia. In addition to consideration of different theoretical approaches to treating these disorders, different ways of including a partner or family in treatment are highlighted: (a) partner-family-assisted interventions, (b) disorder-specific partner-family interventions, and (c) more general couple-family therapy. Findings across diagnostic groups and issues involved in applying efficacy criteria to these populations are discussed.
\end{abstract}

Since the $1970 \mathrm{~s}$, there has been a major shift in knowledge regarding the effectiveness of couple-based and family-based interventions for treating adult mental health problems. During this period, various theoretical perspectives have been articulated, specific manual-based intervention strategies have been developed, and controlled treatment outcome investigations have explored a number of specific issues of importance. The current article examines the empirical status of these couple- and family-based interventions for treating (a) marital distress and (b) adult individual diagnosable disorders. More explicitly, the primary goal of this article is to use the criteria put forth by Chambless and Hollon (1998) to evaluate the efficacy, clinical significance, and effectiveness of various interventions that involve a couple or family format.

The criteria provide a unifying framework for evaluating the wide variety of psychological interventions. As we reviewed the literature on couple- and family-based interventions, we became aware that there were a number of decisions that had to be made with regard to the application of these criteria. Given that other reviewers may have interpreted and applied the Chambless and Hollon (1998) guidelines in a different manner, we begin this

Donald H. Baucom and Anthony D. Daiuto, Psychology Department University of North Carolina, Chapel Hill; Varda Shoham and Timothy R. Stickle, Psychology Department, University of Arizona; Kim T. Mueser, Department of Psychiatry, Dartmouth University Medical School.

We thank Emily Sartor for her assistance in the preparation of this article.

Correspondence concerning this article should be addressed to Donald H. Baucom, Davie Hall CB 3270, Psychology Department, University of North Carolina, Chapel Hill, North Carolina 27599-3270. Electronic mail may be sent via Internet to don_baucom@unc.edu. review by articulating how we have applied them so that the reader can better understand the bases of our conclusions.

One of the major decisions that affects the empirical status of an intervention involves what investigations to include in reviewing the literature. In determining the efficacy status of a treatment, we restricted our consideration to published investigations. Attempts to obtain a comprehensive set of findings from conference presentations, unpublished dissertations, and so forth necessarily result in an incomplete and potentially skewed set of data. At times, unpublished findings are cited if they help to make a certain point or clarify issues, but they are not considered in determining the actual efficacy status of a given treatment. Also, although we included investigations from multiple countries, we restricted our focus to studies published in English. Furthermore, the focus of this article is the treatment of adults who are experiencing psychological distress; consequently, prevention efforts were not reviewed. Such prevention efforts are particularly notable in the marital area, in which a number of recent investigations have explored whether cognitive-behavioral marital interventions can be effectively used with nondistressed couples to prevent marital discord (see Baucom et al., in press, for a review).

A second factor to be considered in selecting studies for inclusion in the review is sample size. As Chambless and Hollon (1998) note, if there is to be adequate power to detect differences among active treatment conditions, approximately $50 \mathrm{cli}-$ ents per condition are needed, although smaller sample sizes in studies demonstrating superiority of one treatment over another are acceptable. When a treatment being investigated proves as efficacious as an already well-established treatment, with no trends for the two conditions to differ, Chambless and Hollon propose a compromise solution to the power problem. If, with 25-30 participants per condition, no patterns favoring the estab- 
lished treatment may be discerned, then it is reasonable to conclude the two treatments are equally efficacious in that study. To give the reader a balanced view of when smaller sample sizes result in treatment differences and when they do not, we include studies with smaller samples in our discussion, regardless of whether significant differences between treatments were found. However, as a result of low power, we did not include studies with small sample sizes to evaluate equivalency among treatment conditions when significant differences were not obtained; in stead, investigations with small samples and null findings are mentioned to make the reader aware of the studies that have been conducted and the findings to date.

Another important decision that can affect efficacy status is whether various investigations are considered to be evaluations of the same treatment or different treatments. This determination is important because Chambless and Hollon's (1998) criteria require that an intervention must be found to be useful in at least two studies conducted by different investigators (along with the bulk of the evidence supporting the intervention) if the intervention is to be considered efficacious. In other words, the status of a given treatment, in terms of empirical support, may depend on subjective judgments about the degree of its similarity to other related interventions. For example, in the treatment of marital discord, both emotion-focused therapy (EFT) and insight-oriented marital therapy (IOMT) are treatments derived from a psychodynamic perspective. The efficacy status of IOMT would shift from possibly efficacious to efficacious depending on whether IOMT and EFT are considered separately or grouped together as psychodynamic marital therapy. Although there is some subjectivity involved, our general strategy has been to consider treatments separately unless they follow the same manual or clearly articulated treatment protocol. According to this guideline, IOMT and EFT involve different intervention techniques and were evaluated separately to determine efficacy status.

Although we concluded that this approach would lead to the clearest understanding of what is known about the efficacy of specific interventions, the nature of the treatments that we reviewed necessitated some exceptions to this overall strategy. First, when findings to date indicated that various specific interventions within a given theoretical framework were equivalent in impact, these various specific interventions were grouped together in determining efficacy status. For example, behavioral marital therapy (BMT) consists of more than one specific intervention strategy (e.g., problem solving and contracting). However, treatment typically involves a combination of these interventions, and existent data have not demonstrated differential effects of specific behavioral interventions. Therefore, they were evaluated collectively as different techniques representative of the behavioral approach to treating marital distress. The second exception to our overall strategy was the family treatment of schizophrenia, which typically lasts for more than a year and includes a number of multifaceted interventions. Because of the length and complexity of this treatment approach, rarely do two studies in this domain use the exact same protocol. Rather than evaluating the efficacy status of each treatment separately, we grouped together and evaluated collectively those with significant overlap in terms of theoretical assumptions and intervention techniques, with attention to the similarities and differences among them.
A final issue with important implications for determining a treatment's efficacy status is the means by which treatment outcomes are determined. This issue has at least two components. First, investigators typically gather outcome data at various time periods, including pretreatment, posttreatment, and a variety of follow-up periods. Consequently, decisions must be made regarding what time periods are relevant for determining efficacy status and how to combine findings that are contradictory across time periods. Second, almost all treatment outcome investigations involve multiple dependent measures, and the results across these various measures are not always consistent. As such, decisions must be made regarding what dependent measures are relevant and how to interpret findings that are contradictory across measures.

Regarding the first of these issues, we decided to determine efficacy status by focusing on changes from pretreatment to posttreatment, recognizing that the long-term effects of treatment are of extreme importance. Our decision was based primarily on methodological difficulties with follow-up data. First, the follow-up time periods used by different investigators vary widely, often ranging from a few months to several years. Drawing a single conclusion about a treatment's efficacy status using such discrepant time periods is difficult and increases the subjective nature of the decision of how to classify a treatment. Second, often there is significant dropout during the follow-up period, further complicating initial low power and the possibility of differential dropout between conditions, which can significantly affect the findings. Third, although most investigators seem to disallow additional intervention outside of the treatment protocol while treatment is actually occurring, clients typically are free to seek additional treatment during the follow-up period, which makes it difficult to evaluate the long-term effects of the stated treatment. In addition, few investigators track or report whether clients have obtained additional treatment during the follow-up period; therefore, it is difficult to evaluate the extent of this potential confound. Although we focus on pretest and posttest measures to determine efficacy status, we include a discussion of the long-term effects of treatment when such data are available. Again, there are exceptions to this general focus on posttest evaluations in our analysis; in some instances, longterm relapse is the specific outcome of interest (e.g., in treating schizophrenia). In such instances, efficacy status is based on these long-term outcomes.

In determining efficacy status when multiple dependent measures are used within and across studies, we attempted to select a set of central or core dependent variables that are generally agreed on as major criteria of improvement and that are used across investigations in a given area of investigation. For example, in the treatment of marital distress, almost all investigators would agree that the couple's overall marital adjustment or marital satisfaction at the end of therapy is an important index of the treatment's impact. Therefore, marital adjustment-satisfaction is the criterion focused on in determining efficacy status for the treatment of marital discord. Various theoretical approaches might differentially emphasize other constructs (e.g., communication skills or intimacy) in assessing the impact of treatment. Whereas the effects of treatment in altering these other aspects of functioning are noted, efficacy status is determined by change in the core or central criteria noted in each subsequent section.

In evaluating the efficacy status of couple and family interven- 
tions, we used the following categories based on Chambless and Hollon's (1998) criteria. If an intervention has been found to be superior to a wait list control condition in at least two studies conducted by two independent research teams (and the bulk of the findings support these results), it is designated as efficacious. If the intervention has been found to be superior to a placebo, nonspecific treatment, or rival interventions in two studies conducted by independent research teams, it is designated as efficacious and specific. It is important to recognize that the use of the term specific in this instance does not imply that an intervention is the treatment of choice for a given disorder; instead, it might indicate only that a treatment was superior to a placebo condition in two investigations. These two categories ("efficacious" and "efficacious and specific") are modified with the term possibly when all other criteria are met for a designation but only one study has been conducted (or two or more by a single research team). Thus, if a treatment has been found to be superior to a wait list in a single study, it is labeled possibly efficacious. If a treatment has been found to be superior to a rival treatment in a single study, it is termed possibly efficacious and specific. If a treatment has been found to be superior to a wait list in one study and superior to a rival treatment in another study by another investigative team, it meets criteria for efficacy but is only possibly specific; thus, it is termed efficacious and possibly specific.

In addition to focusing on the efficacy status of various interventions, we discuss findings related to effectiveness and clinical significance when possible. The different domains of investigation included in this review vary widely in the extent to which researchers have focused on these issues. Consequently, when discussions of effectiveness or clinical significance are omitted in a given section, the reader can assume that there currently are not data that address these issues.

\section{Couples' Therapy for Relationship Distress}

The most basic question to ask regarding marital therapy is whether the interventions are efficacious in treating the marital problems reported by distressed couples. Whereas this might at first appear to be a straightforward question, in actuality it is more complex. What are the criteria for efficacy in this instance? There are at least two ways to alter marital distress: (a) helping the couple become more satisfied with their current relationship or (b) assisting the couple in terminating a relationship that is not healthy or rewarding for the persons involved (Baucom, Burnett, Rankin, \& Sher, 1990; Jacobson \& Addis, 1993). Unfortunately, at present there are no criteria to assist in determining when the termination of a relationship is the outcome of choice. Consequently, consistent with the perspective of most marital therapy outcome investigators, increases in marital adjustment or marital satisfaction were used as the criterion of central importance in evaluating the efficacy of marital therapy for relationship distress. Similarly, divorce was interpreted as a negative outcome while recognizing that, for specific couples, divorce might represent a positive resolution to an unhealthy or ungratifying relationship.

\section{Behavioral Marital Therapy}

By far the most widely evaluated marital treatment is BMT, which has served as a focus of more than two dozen well- controlled treatment outcome studies. BMT has been presented as a skills-oriented approach emphasizing that couples need basic skills and understanding of relationship interactions to improve their marriages. The treatment focuses primarily on the current marital relationship, teaching couples how to communicate with each other and solve problems more effectively. In addition, the therapist assists the couple in planning behavioral changes to increase the frequency of pleasing interactions while minimizing destructive, negative interactions. This can include caring or loving acts toward the partner as well as increases in coupling activities such as taking walks, attending the theater, and so forth. At times, these behavior change or behavior exchange strategies have incorporated various forms of contracting in which there are contingencies for following through with agreed-on behavior changes. These interventions have been outlined in a number of treatment manuals (e.g., Baucom \& Epstein, 1990; Jacobson \& Margolin, 1979; R. B. Stuart, 1980).

As noted earlier, BMT is not a single intervention strategy. Rather, it is an approach to treatment based on social learning principles. A number of interventions have been developed that focus primarily on (a) behavior exchange strategies, such as teaching couples how to contract for reciprocal behavior changes or suggesting increases in joint couple recreational activities, and (b) communication and problem-solving skills. Although there are differences among these interventions, almost all focus on the present, deal with behaviors and interaction patterns that are in the couple's awareness, involve specific behavioral changes to promote more adaptive functioning, and incorporate homework or the application of behavioral principles outside of the session. Several investigations have been conducted comparing these specific interventions with each other as components or with the full BMT intervention (e.g., Baucom, 1982; Emmelkamp, van der Helm, MacGillavry, \& van Zanten, 1984; Ewart, 1978; Hahlweg, Schindler, Revenstorf, \& Brengelmann, 1984; Jacobson, 1978, 1984). Most of these investigations involved rather small sample sizes, thus making it difficult to detect between-groups differences. These studies generally found no significant differences between treatments when the components were directly compared (see Table 1 for details ). In their meta-analyses, Hahlweg and Markman (1988) and Shadish et al. (1993) compared the effect sizes from various behavioral interventions and concluded that the various BMT interventions had equal impacts. Thus, although the investigations are based on relatively small sample sizes, no single behavioral intervention has been isolated as necessary to promote effective treatment. Consequently, the efficacy status of BMT is determined by considering it as a broad treatment approach.

\section{Efficacy Status}

BMT has been reviewed in detail in a number of previous articles, and findings from specific investigations (e.g., Alexander, Holtzworth-Munroe, \& Jameson, 1994; Baucom \& Epstein, 1990; Baucom \& Hoffman, 1986; Bray \& Jouriles, 1995; Jacobson \& Addis, 1993; Lebow \& Gurman, 1995) as well as metaanalyses of marital therapy (Dunn \& Schwebel, 1995; Hahlweg \& Markman, 1988; Shadish et al., 1993) have been included. These various reviews have used different criteria for evaluating efficacy, but they have all reached the same conclu- 
Table 1

Empirical Status of Marital Therapy for the Treatment of Marital Distress

\begin{tabular}{cccc}
\hline Treatment & Study & Treatment conditions $_{\text {Major results }}{ }^{\mathrm{a}}$ \\
\hline
\end{tabular}

\section{BMT}

Azrin et al. (1980)

Baucom (1982)

Baucom \& Lester (1986)

Baucom, Sayers, \& Sher (1990)

Bennun (1985)

Boelens, Emmelkamp, MacGillavry, \& Markvoort (1980)

Crowe (1978)

Emmelkamp et al. (1984)

Emmelkamp et al. (1988)

Ewart (1978)

Girodo et al. (1980)

Hahlweg et al. (1982)

Halford et al. (1993)

Jacobson (1977)

Jacobson (1978)

Jacobson (1984)

S. M. Johnson \& Greenberg (1985)

Efficacious and specific treatments

1. BMT $(n=28)$

2. Attention-placebo $(n=27)$

1. $\operatorname{BMT}(n=18$ )

2. Communication-problem solving $(n=18)$

3. Behavioral contracting $(n=18)$

4. Wait list $(n=18)$

1. $\operatorname{BMT}(n=8)$

2. BMT + cognitive restructuring $(n=8)$

3. Wait list $(n=8)$

1. BMT + cognitive restructuring for couples + emotional expressiveness training $(n=12)$

2. $\mathrm{BMT}(n=12)$

3. BMT + cognitive restructuring for couples $(n=12)$

4. BMT + emotional expressiveness training $(n=12)$

5. Wait list $(n=12)$

1. Conjoint BMT $(n=19)$

2. Group BMT $(n=19)$

3. Individual BMT $(n=19)$

1. Behavioral contracting $(n=8)$

2. Systematic therapy $(n \doteq 8)$

3 . Wait list $(n=5)$

1. BMT $(n=14)$

2. Group analytic therapy $(n=14)$

3. Attention-placebo $(n=14)$

1. Communication-problem solving + behavioral contracting

2. Behavioral contracting + communication-problem solving $(n=17)$

1. BMT $(n=16)$

2. Cognitive restructuring for couples $(n=16)$

1. BMT $(n=18)$

2. Wait list $(n=6)$

1. BMT $(n=6)$

2. Minnesota Couples' Communication Program $(n=12)$

3. Wait list $(n=6)$

1. BMT $(n=17)$

2. Group BMT $(n=16)$

3. Emotional expressiveness training $(n=16)$

4. Group emotional expressiveness training $(n=19)$

5. Wait list $(n=17)$

1. BMT $(n=13)$

2. BMT + cognitive restructuring + affect exploration + generalization training $(n=13)$

1. BMT $(n=5)$

2. Wait list $(n=5)$

1. BMT + good faith behavioral contracting $(n=8)$

2. BMT + quid pro quo behavioral contracting $(n=9)$

3. Attention-placebo $(n=7)$

4. Wait list $(n=6)$

1. $\operatorname{BMT}(n=9)$

2. Communication-problem solving $(n=9)$

3. Behavior exchange $(n=9)$

4. Wait list $(n=9)$

1. EFT $(n=15)$

2. Communication-problem solving $(n=15)$

3. Wait list $(n=15)$
$1>2$

$1=2=3>4$

$1=2>3$

$1=2=3=4>5$

$1=2=3$

$1=2>3$

$1=2=3$

$1=2$

$1=2$

Women: $1>2$

Men: $1=2$

$1=2=3$

$1=2=3>4=5$

$1=2$

$1>2$

$1=2>3,4$

$1=2=3>4$

$1>2>3$ 
Table 1 (continued)

\begin{tabular}{|c|c|c|c|}
\hline Treatment & Study & Treatment conditions & Major results ${ }^{2}$ \\
\hline \multicolumn{4}{|c|}{ Efficacious and specific treatments (Continued) } \\
\hline & Liberman et al. (1976) & $\begin{array}{l}\text { 1. BMT }(n=5) \\
\text { 2. Attention placebo }(n=4)\end{array}$ & $1>2$ \\
\hline & Synder \& Wills (1989) & $\begin{array}{l}\text { 1. BMT }(n=29) \\
\text { 2. Insight-oriented marital therapy }(n=30) \\
\text { 3. Wait list }(n=20)\end{array}$ & $1=2>3$ \\
\hline & Tsoi-Hoshmand (1976) & $\begin{array}{l}\text { 1. BMT }(n=10) \\
\text { 2. Attention-placebo }(n=6) \\
\text { 3. Wait list }(n=4)\end{array}$ & $\begin{array}{l}2=3 \\
1>2,3\end{array}$ \\
\hline & Turkewitz \& O'Leary (1981) & $\begin{array}{l}\text { 1. Emotional expressiveness training }(n=10) \\
\text { 2. BMT }(n=10) \\
\text { 3. Wait list }(n=10)\end{array}$ & $1=2=3$ \\
\hline & Wilson et al. (1988) & $\begin{array}{l}\text { 1. Group BMT }(n=5) \\
\text { 2. Conjoint BMT }(n=5) \\
\text { 3. Wait list }(n=5)\end{array}$ & $1=2>3$ \\
\hline
\end{tabular}

Efficacious and possibly specific treatments

1. EFT $(n=12)$

2. Waring cognitive therapy $(n=12)$

3. Wait list $(n=12)$

\author{
A. Goldman \& Greenberg \\ (1992)
}

1. $\operatorname{EFT}(n=14)$

2. Systemic therapy $(n=14)$

James (1991)

Johnson \& Greenberg (1985)

Walker et al. (1996)

1. EFT + emotional expressiveness training ( $n=14)$
2. EFT $(n=14)$

3. Wait list $(n=14)$

See above entry under BMT

1. EFT $(n=16)$

2. Wait list $(n=16)$
3. Wait list $(n=14)$

$1=2=3$

$1=2>3$

$1=2>3$

Possibly efficacious treatments

Cognitive therapy

Emmelkamp et al. (1988)

Huber \& Milstein (1985)

See above entry under BMT

1. Cognitive restructuring for couples $(n=9)$

$1>2$

2. Wait list $(n=8)$

See above entry under BMT

behavioral therapy

Baucom \& Lester (1986)

Baucom et al. (1990)

See above entry under BMT

Halford et al. (1993)

Insight-oriented

Snyder \& Wills (1989) therapy

Systemic therapy
See above entry under BMT

See above entry under BMT

See above entry under EFT
A. Goldman \& Greenberg (1992)

Note. $\mathrm{BMT}=$ behavioral marital therapy $\mathrm{EFT}=$ emotion-focused therapy.

${ }^{a}$ Major results include statistically significant differences among treatment conditions at posttest; see text for follow-up results. Treatments are designated by number from previous column (e.g., $1>2$ indicates that Treatment 1 is statistically superior to Treatment 2 in improving marital adjustment at posttest).

sion: BMT is an efficacious intervention for treating maritally distressed couples.

This conclusion appears justified when the current empirically supported treatment (EST) criteria, focusing on marital adjustment-satisfaction as the outcome criterion, are used. A large number of investigations have compared BMT with wait list control conditions, finding rather consistently that BMT is more effective than a waiting list in altering marital adjustment (see Table 1 for details). Several early investigations of BMT also compared it with nonspecific or placebo treatment conditions and generally found BMT to be more efficacious than nonspecific treatment conditions (Azrin et al., 1980; Crowe, 1978; Jacobson, 1978). Additional details of these investigations are outlined in Table 1. 
The findings from this box score approach (i.e., tallying the number of studies demonstrating BMT to be more effective than control conditions relative to the number of studies demonstrating no differences) are confirmed by the results of meta-analyses conducted by Hahlweg and Markman (1988), Shadish et al. (1993), and Dunn and Schwebel (1995). On the basis of 17 controlled outcome studies using BMT, Hahlweg and Markman found that, relative to placebo or waiting list treatments, BMT resulted in a mean effect size of 0.95 . This means that the average person who received BMT had higher scores on a variety of marital indexes at posttest than $83 \%$ of the partners in a placebo or waiting list control condition. On the basis of a similar analysis 5 years later that included additional studies, Shadish et al. (1993) obtained an identical effect size of 0.95 . Hahlweg and Markman demonstrated that the greatest effects are obtained when BMT is compared with a waiting list condition. BMT demonstrated an average effect size of 1.02 relative to waiting list conditions; the average effect size was only 0.55 when BMT was compared with nonspecific placebo conditions. Dunn and Schwebel (1995) reported an effect size of 0.79 for BMT in comparison with all control conditions. When considered in total, the bulk of the evidence indicates that, on the basis of posttreatment data, BMT meets criteria as an efficacious and specific intervention for marital distress.

\section{Follow-Up Results}

The maintenance of treatment effects for BMT also has been explored, but in many fewer studies. On the basis of five studies with follow-ups of 9-12 months, Hahlweg and Markman (1988) concluded that, relative to control conditions, BMT had posttest and follow-up mean effect sizes of 1.07 and 1.16 , respectively. These findings indicate that the effects of BMT are maintained during the 1st year after treatment, although the stable results involve the group effects overall and not necessarily specific couples.

However, results from longer follow-up periods are not as encouraging. In a 2-year follow-up of BMT, Jacobson, Schmaling, and Holtzworth-Munroe (1987) found that approximately $30 \%$ of couples who had recovered during therapy had subsequently relapsed. In addition, Snyder, Wills, and Grady-Fletcher (1991) reported that $38 \%$ of couples receiving BMT had divorced during a 4-year follow-up period. Thus, it cannot be assumed that the effects of relatively brief BMT (average of 11 sessions; Hahlweg \& Markman, 1988) will be maintained for all couples over a number of years, although the changes in adjustment are stable for some couples.

\section{Clinical Significance}

The preceding criteria for establishing efficacy are based on comparisons of group means; thus, a treatment is deemed to be efficacious if it is superior to no treatment or nonspecific treatments in the bulk of the investigations conducted. The efficacy criteria do not consider whether the magnitude of change produced by the treatment is in some manner clinically significant or worth noting in terms of a couple's day-to-day functioning. Jacobson, Follette, and Revenstorf (1984) suggested two related criteria for assessing the clinical significance of changes in marital adjustment. First, a couple is categorized as "improved" if their score on a measure of relationship adjustment changes more than would be expected on the basis of measurement error alone (see L. Christensen \& Mendoza, 1986, for a modification of Jacobson et al.'s original formula); thus, the change appears to be real in a statistical sense. The second criterion is whether the magnitude of this reliable change has an impact on the couple's life. This is determined by whether the couple's score on the measure of marital adjustment moves from the distressed to the nondistressed range (see also Kendall \& Grove, 1988). If both of these criteria are met, the change is deemed clinically significant.

Applying these criteria, Jacobson, Follette, Revenstorf, Baucom et al. (1984) explored the clinically significant changes experienced by couples receiving BMT in three large outcome investigations conducted by three different investigators (Baucom, 1982; Hahlweg, Revenstorf, \& Schindler, 1982; Jacobson, 1984). They found that $56 \%$ of couples receiving BMT improved at posttest beyond measurement error and that $35 \%$ of the treated couples were no longer distressed at posttest; only $13.5 \%$ of waiting list couples demonstrated reliable improvement. During a 6-month follow-up period, the majority of couples maintained their treatment gains ( $59 \%$ ); an additional $14 \%$ demonstrated further improvement during the follow-up period, and $28 \%$ of the couples deteriorated during follow-up. More recent investigations using similar statistical methodologies have reported somewhat more favorable findings. For example, Halford, Sanders, and Behrens (1993) found that 54\% of husbands and $42 \%$ of wives were no longer in the distressed range at the end of treatment. Snyder et al. (1991) reported that $66 \%$ of couples receiving BMT were happily married at posttest, and $50 \%$ continued to be happily married 4 years later (however, these more optimistic numbers reported by Snyder et al. must be tempered by the high divorce rate for BMT couples at 4year follow-up described earlier). Although there is variability among studies, the findings overall suggest that between one third and two thirds of couples receiving BMT are likely to be in the nondistressed range at the end of treatment. Most couples appear to maintain these gains for short time periods (6 to 12 months), but, based on limited data requiring replication, a proportion of these couples can be expected to demonstrate relapse 2 to 4 years after treatment.

\section{Effectiveness}

A number of additional issues regarding the clinical utility and efficient implementation of BMT have been evaluated. Although the majority of BMT investigations do not report data on consumers' satisfaction with BMT, the findings of a small number of studies suggest that couples rate the treatment positively and continue with the intervention. For example, Hahlweg et al. (1982) reported that $91 \%$ of couples saw the therapy as a "worthwhile experience," and 94\% would recommend the treatment to a friend. Dropout rates also appear to be low. On the basis of the results of seven BMT outcome studies, Hahlweg and Markman (1988) concluded that there is an attrition rate of only $6 \%$.

Whereas couples who receive BMT appear to be pleased with the intervention and persist through treatment, it is also important to know who seeks intervention and in what settings. On the basis of 17 BMT outcome studies, Hahlweg and Mark- 
man (1988) found that couples receiving BMT in outcome studies are predominantly middle class, with an average age of 32 years and 7.5 years of marriage; $70 \%$ of the couples had at least one child. However, the overall effects of BMT with young, middle-class couples have been replicated with couples who, on average, are older (average age of 41.6 years), less well educated (average of 12.5 years of education), and of lower socioeconomic status (lower middle class; Halford et al., 1993). Results from investigations also appear similar when compared across the United States, Germany, Australia, Holland, Great Britain, and Canada. In fact, Hahlweg and Markman (1988) found no significant differences in their meta-analysis when comparing BMT provided to European couples and BMT offered in the United States. Unfortunately, nothing is known about the effectiveness of these interventions with ethnic minorities or in same-gender relationships. In addition, although there is a tendency to replace the term marital therapy with couples therapy to recognize committed couples who are not legally married, almost all of the studies have been based on legally married couples. Hahlweg and Markman (1988) also indicated that the majority of couples in BMT outcome studies were recruited from advertisements and that only $19 \%$ involved referrals from professionals. However, in their meta-analysis of 163 marital and family therapy studies (not specific to BMT), Shadish et al. (1993) concluded that the referral source of clients and the use of university-based clients did not moderate the effects of marital and family therapy overall.

Finally, although the vast majority of investigations have evaluated BMT implemented in a conjoint format, the demands of clinical practice might require that BMT be delivered in alternate ways. For example, therapists in a community setting might find that it is more cost-effective to provide BMT in a group context rather than treat one couple at a time. Three controlled investigations have been conducted comparing the effectiveness of conjoint group (several couples together in group marital therapy) and conjoint marital therapy (one couple meets with a therapist; Bennun, 1985; Hahlweg et al., 1984; Wilson, Bornstein, \& Wilson, 1988). All three investigations concluded that BMT offered in a conjoint group context was effective in alleviating marital distress; however, the findings from Hahlweg et al. and Bennun suggested that BMT in a conjoint format is likely to be more powerful or work more rapidly than BMT in a conjoint group format.

\section{Cognitive and Cognitive-Behavioral Marital Therapy}

Although it is generally recognized that behavior, cognition, and emotion are important factors in marital functioning, the applications of BMT discussed earlier place a primary emphasis on altering behavior as the primary strategy for improving marital functioning. BMT follows from the premise that, because all three domains are interrelated, behavioral changes should result in different ways of thinking about the partner and the marriage, along with concomitant shifts in feelings about the marriage. Concurrent with a generally increasing emphasis on cognitive factors in psychological functioning, marital investigators recently have begun to explore the role of cognitions in marital functioning (e.g., Baucom, Epstein, Sayers, \& Sher, 1989; Bradbury \& Fincham, 1990). This interest in cognitive factors in marriage has spawned a variety of cognitive treatment interventions that attempt to help spouses think about and understand their relationship and each partner's behavior in a different, less destructive manner. This includes, for example, helping spouses to consider alternative attributions or explanations for why their partners might behave in a negative manner. Similarly, if their expectations about marriage appear to be unrealistic, spouses might be asked to reevaluate their standards for what a marriage should be. These types of cognitive interventions have been used in two major ways: (a) as the primary set of interventions used in assisting couples (cognitive restructuring [CR]) or (b) as a supplement to BMT (cognitive-behavioral marital therapy).

\section{Cognitive Marital Therapy}

Huber and Milstein (1985) compared cognitive marital therapy with a waiting list control condition. The cognitive marital therapy focused primarily on irrational relationship standards and assumptions highlighted by Epstein and Eidelson (1981), along with selected irrational beliefs viewed to be pertinent to marriage, as noted by Ellis (1977). The findings indicated that cognitive marital therapy for 6 weeks was more effective than the waiting list condition in improving marital adjustment. On the basis of these findings, cognitive therapy (CT) for distressed couples should be classified as a possibly efficacious treatment for marital distress.

\section{Cognitive-Behavioral Marital Therapy}

Whereas the cognitive marital therapy just discussed included only cognitive techniques, some investigators have attempted to strengthen the effectiveness of BMT by supplementing it with cognitive interventions.

Efficacy status. Baucom and colleagues (Baucom \& Lester, 1986; Baucom, Sayers, \& Sher, 1990) supplemented BMT with cognitive restructuring interventions targeted at couples' attributions for marital events and their standards for what marriage should be. In the first of two investigations designed to evaluate this treatment, Baucom and Lester randomly assigned 24 distressed couples to (a) BMT alone, (b) CR followed by BMT (CR + BMT), or (c) a waiting list condition. In a later investigation, Baucom et al. implemented BMT and CR in conjunction with emotional expressiveness training (EET), which was designed to teach spouses how to communicate important thoughts and feelings and listen empathically to each other. Couples were taught to use these communication skills in conversations in which they were not attempting to resolve a problem. Sixty distressed couples were randomly assigned to one of five treatment conditions: (a) BMT alone, (b) CR + BMT, (c) BMT + EET, (d) CR + BMT + EET, or (e) a waiting list condition. In both of these studies, the findings indicated that the various treatments were more effective than a waiting list in altering marital adjustment, improving communication, and altering presenting complaints, but there were no significant differences among the active treatment conditions. The sample size lacked power to adequately detect differences among these treatments; however, there were no meaningful trends to suggest that a larger sample size would have altered the findings.

In a similar investigation, Halford et al. (1993) assigned 26 married couples to one of two treatment conditions: BMT or 
enhanced BMT. Enhanced BMT included cognitive restructuring procedures taken from Baucom and Lester (1986) and Baucom and Epstein (1990), as well as generalization training and affect exploration. The affect exploration component involved the spouses' exploration of their feelings about difficult marital interactions in conjunction with therapist interpretations about recurrent relationship and personal themes. Generalization training taught couples how to apply their new skills to important, high-risk situations in their daily lives. Findings indicated that both treatments resulted in increases in marital adjustment; treatment effects were consistent across both clinic and home settings. However, there were no significant differences between the two treatment conditions, possibly as a result of the rather small sample size.

In summary, all three of the studies just described involved rather small sample sizes, but the magnitude of change produced for various dependent measures appears to be consistent with what has been found in a number of BMT investigations. Thus, to date, the findings suggest that supplementing BMT with CR is as efficacious as BMT alone but does not produce enhanced treatment outcomes. The combination of BMT and CR has been found to be more effective than a waiting list condition by only one research team and, therefore, is most appropriately classified as possibly efficacious.

Clinical significance. In examining clinically significant changes, Halford et al. (1993) found no significant differences between treatment conditions at either posttest or follow-up. Across the two treatment conditions, approximately $70 \%$ of the couples improved, and approximately $50 \%$ of the couples were no longer distressed at the end of therapy. Across their two investigations, Baucom and colleagues found no significant differences between response rates for couples receiving BMT or BMT + CR. Fifty-four percent of the couples receiving the combined treatment improved, and $42 \%$ of the couples were no longer distressed at the end of treatment. Thus, findings to date suggest that BMT + CR results in changes that are comparable to those of BMT in terms of clinical significance.

\section{Emotion-Focused and Insight-Oriented Marital Therapy}

In contrast to the skills-oriented focus of behavioral and cognitive-behavioral marital interventions, psychodynamic and insight-oriented approaches to marital therapy place an emphasis on couples gaining understanding and insight, along with sharing important feelings with each other regarding issues that underlie their dysfunctional interaction patterns. At least two psychodynamic insight-oriented approaches have been developed and empirically investigated: Snyder and Wills's (1989) IOMT and Greenberg and Johnson's (1988) EFT. The two approaches have some important differences: (a) EFT was developed specifically within attachment theory, whereas IOMT was not, and (b) IOMT places greater emphasis on material that is totally or partially beyond awareness or on an unconscious level. Still, the two treatments have much in common. Perhaps most important, both ask spouses to explore the feelings, thoughts, and needs that are believed to underlie their current distress. Both treatments view sharing these more vulnerable aspects of oneself with one's partner as central to the partner's gaining greater empathy and understanding, which then frees the couple to interact in different ways. Thus, both treatments are concerned with the couple's current interaction, but this interaction pattern becomes alterable when the couple's underlying needs and reasons for behaving negatively are made explicit within the context of expressing emotions.

\section{Insight-Oriented Marital Therapy}

In differentiating IOMT from BMT, Snyder and Wills (1989) described IOMT as follows:

IOMT emphasized the resolution of conflictual emotional processes that exist either within one or both spouses separately, between spouses interactively, or within the broader family system. This approach attempted to integrate individual, couple, and family functioning by addressing developmental issues, collusive interactions, incongruent contractual expectations, irrational role assignments, and maladaptive relationship rules. Therapists used probes, clarifications, and interpretation in uncovering and explicating those feelings, beliefs, and expectations that spouses had toward thenselves, their partners, and their marriage, which were either totally or partially beyond awareness, so that these could be restructured or renegotiated at a conscious level. (p. 41)

Efficacy status. Snyder and Wills (1989) compared the relative effectiveness of IOMT and BMT in a treatment study involving 79 maritally distressed couples ( 29 in BMT, 30 in IOMT, and 20 waiting list couples). They found both treatments to be efficacious (relative to the waiting list condition), but there were no differences between BMT and IOMT in altering marital adjustment at posttest. BMT and IOMT showed effect sizes of 1.01 and 0.96 , respectively. On the basis of the superiority of IOMT to the waiting list couples in this one investigation, IOMT is categorized as possibly efficacious.

Follow-up results. IOMT and BMT were comparable on marital adjustment at 6-month follow-up, but the findings changed significantly when long term follow-up was considered. In the longest follow-up to date on the efficacy of marital therapy, Snyder et al. (1991) recontacted $96 \%$ of their treated couples 4 years after the completion of therapy. At this 4-year follow-up, significantly more BMT couples (38\%) than IOMT couples $(3 \%)$ had experienced divorce. Similar patterns were found when levels of marital adjustment were considered: At 4year follow-up, IOMT couples demonstrated significantly higher levels of marital adjustment than BMT couples. Unfortunately, it is unknown whether couples received additional interventions during this follow-up period.

Clinical significance. The clinical significance data mirror the findings just described. At posttest, there were no significant differences in response rates between IOMT and BMT. Using a variant of Jacobson, Follette, and Revenstorf's ( 1984) criteria for clinical significance, the authors found that $73 \%$ of IOMT, $62 \%$ of BMT, and $15 \%$ of waiting list couples demonstrated significant improvement; $40 \%$ of IOMT, $55 \%$ of BMT, and $5 \%$ of waiting list couples were no longer distressed at posttest. However, at 4-year follow-up, BMT demonstrated significantly higher rates of deterioration than IOMT. Whereas the percentage of couples improving from intake to 4-year follow-up was not drastically different for the two treatments $(42 \%$ and $52 \%$ for BMT and IOMT, respectively), it appears that a large number of couples receiving BMT deteriorated during the 4 years (39\% for BMT vs. $10 \%$ for IOMT). These findings do not appear to 
result from the inclusion of a weak version of the BMT treatment. The effect size of 1.01 for BMT at posttest is almost identical to the average effect size of BMT across a wide range of investigations.

\section{Emotion-Focused Therapy}

EFT emphasizes the centrality of emotion in marital distress and in marital therapy (Greenberg \& Johnson, 1988; S. M. Johnson \& Greenberg, 1994, 1995). Based on attachment theory, EFT views distressed relationships as "insecure bonds in which essentially healthy attachment needs are unable to be met due to rigid interaction patterns that block emotional engagement", (S. M. Johnson \& Greenberg, 1995, p. 121). Therapy proceeds with helping each partner to explore and communicate his or her emotional experience around issues such as affiliationcloseness and control-dependence within the context of the current relationship. EFT assumes that as these valid attachment needs are made clear, each person will understand himself or herself in new ways and view his or her partner differently and more sympathetically. This will then lead to new, less defensive interaction patterns between the partners.

Efficacy status. There have been several investigations of EFT addressing various issues about its efficacy, and the findings to date indicate that EFT is of significant benefit to distressed couples. S. M. Johnson and Greenberg (1985) assigned 45 maritally distressed couples to (a) EFT, (b) BMT, or (c) a waiting list condition. It is important to note that the interventions were restricted to moderately distressed couples because the investigators were concerned that EFT might not be optimal for extremely distressed couples. The findings demonstrated that, even with relatively small sample sizes, EFT was superior to BMT in increasing marital adjustment at posttest.

In another investigation of the efficacy of EFT, A. Goldman and Greenberg (1992) compared the relative effectiveness of (a) EFT, (b) systemic couples therapy, and (c) a waiting list condition ( $n=14$ couples per treatment condition). The focus of the systemic couples therapy was on changing couple interactions by reframing or positively connoting the couples' symptoms or the functioning of the system and interrupting vicious behavioral cycles by prescribing the symptom or the pattern of interaction targeted for change. The findings indicated that the two treatment conditions were equally effective and superior to the wait list condition in altering marital adjustment; it should be noted that the small sample size reduced the likelihood of obtaining statistically significant differences between the active treatment conditions. (The findings from this single investigation place systemic couples therapy into the category of possibly efficacious.)

James (1991) compared EFT with an enhanced version of EFT, along with a wait list condition. James proposed that including a communications skills component to EFT might provide a stronger treatment with greater maintenance. Thus, he compared EFT and a combined treatment of EFT along with communications training. The communications training condition was similar to the EET treatment component used by Baucom, Sayers, et al. (1990) as an addition to BMT. Based on 14 moderately distressed couples in each of the three treatment conditions, the findings indicated that each of the treatment conditions was superior to the waiting list condition in terms of marital adjustment at posttest. The two active treatment conditions did not differ from each other at posttest on marital adjustment, but the small sample sizes and lack of power in the study make this finding difficult to interpret.

On the basis of the consistent posttest superiority of EFT to. wait list couples across studies involving investigators from more than one research team, EFT should be viewed as an efficacious treatment for assisting maritally distressed couples. Given its superiority to the efficacious BMT treatment in the S. M. Johnson and Greenberg (1985) investigation, it also is possibly specific and superior to other forms of efficacious treatment.

Follow-up results. When EFT is restricted to moderately distressed couples, posttest findings appear to be relatively unchanged at follow-up: S. M. Johnson and Greenberg (1985) found EFT to be superior to BMT at 2-month follow-up, as well as at posttest, and James (1991) found that EFT and enhanced EFT were similar at both posttest and follow-up. However, this pattern of findings was different in the one investigation that involved more distressed couples. A. Goldman and Greenberg (1992) found that EFT and systemic couples therapy were not different from each other at posttest; at 4-month followup, however, the systemic therapy was superior to EFT. This difference between treatments resulted from the couples in the EFT treatment experiencing significant relapse during the follow-up period. The investigators noted that couples in this study were much more distressed than couples in the Johnson and Greenberg study, which might account for the differences seen in the two studies at follow-up. They cautioned that, with severely distressed couples, time-limited EFT might not be powerful enough to create sufficient intimacy to maintain posttest gains. Thus, the findings from this study seem to confirm Johnson and Greenberg's suggestion that EFT might not be appropriate for severely distressed couples, at least in the long term. In addition, not only have the strongest follow-up findings been demonstrated with less maritally distressed couples, but some of the preceding studies excluded individuals with psychiatric histories, again probably ruling out more difficult cases.

Clinical significance. Using the methodology proposed by Jacobson, Follette, and Revenstorf, (1984), James (1991) reported that approximately $90 \%$ of couples receiving the two versions of EFT improved with treatment, and $75 \%$ were no longer distressed at the end of treatment. These response rates appear to be quite high, particularly in comparison with response rates from BMT investigations. However, these comparisons with BMT investigations must be interpreted cautiously because it appears that James was investigating a somewhat different population of couples. Whereas $50 \%$ of James's waiting list couples improved without treatment, the waiting list couples in the BMT studies reviewed by Jacobson et al. showed an improvement rate of only $13.5 \%$. This marked tendency of couples to improve without treatment in James's study might have resulted from his limiting his sample to moderately distressed couples.

Effectiveness. One issue in evaluating a treatment is assessing the degree to which it is generalizable across populations. Recently, Walker, Johnson, Manion, and Cloutier (1996) applied EFT to couples with chronically ill children. Couples were assigned either to EFT or to a waiting list control group ( $n=16$ couples per group). EFT was adapted to include a 
specific focus on dealing with chronically ill children as part of the content of the sessions, along with EFT as practiced in other studies. The findings indicated that EFT was more effective than the waiting list condition in increasing marital adjustment at posttest. When Walker et al. used a somewhat higher cutoff point for marital distress that they viewed as appropriate for parents of chronically ill children, $75 \%$ of the couples improved, and $38 \%$ moved into the nondistressed range. Pretreatment marital adjustment scores in the Walker et al. study were even substantially higher than in the S. M. Johnson and Greenberg (1985) study, demonstrating again the effectiveness of EFT with mildly to moderately distressed couples.

As noted earlier, EFT appears to be quite beneficial for couples who are mildly or moderately distressed. Yet, in the one investigation that included more distressed couples, there was substantial relapse during follow-up. Consequently, it will be important to explore further whether EFT is appropriate for highly distressed couples or whether it should be used primarily with less distressed couples who have maintained some sense of attachment to each other.

\section{Conclusions}

On the basis of the treatment outcome studies conducted to date, both BMT and EFT can be viewed as efficacious for treating marital distress; BMT is efficacious and specific, and EFT is efficacious and possibly specific. IOMT, cognitive-behavioral marital therapy, CT for couples, and couples' systemic therapy all meet criteria for possibly efficacious treatments. All of the previously noted intervention strategies have been found to be superior to a wait list treatment condition; consequently, it can be seen that providing treatment to distressed couples is a fruitful use of professional time. It is important to note, however, that there is less evidence regarding two equally important questions: First, is one form of marital therapy more efficacious than the others overall? Second, how should a clinician select from the interventions the one that is most appropriate for a given couple?

This first question is approached by directly comparing different active treatment conditions. To the extent to which there has been exploration within the behavioral domain, different interventions from a similar theoretical perspective have not been found to be significantly different overall. However, when different theoretical approaches have been compared, some intriguing findings have resulted that warrant consideration. In two investigations in which behavioral interventions were compared with marital therapy based on insight-oriented approaches, the insight-oriented approaches were superior at follow-up (EFT at short-term follow-up and IOMT at long-term followup). These findings must be viewed cautiously for at least three reasons: (a) Neither of the findings have been replicated; (b) as is typical of the marital therapy research field, no assessment was made to clarify whether couples had sought additional intervention during the follow-up period; and (c) in both instances, the treatment that was found to be superior was the theoretical orientation of the principal investigator. Thus, unintended allegiance effects could have had an impact on the findings (Chambless \& Hollon, 1998). On the other hand, one should not dismiss the possibility that the findings reflect important information. These results could suggest that skills training from a behavioral perspective with maritally distressed couples is of use to a large number of couples, but skills training alone might not maintain treatment gains for some couples. In fact, efforts to broaden a stricter behavioral model (e.g., cognitive-behavioral intervention strategies and Jacobson \& Christensen's, 1996, integrative couples therapy) have resulted from a belief that skills training alone focusing on behavior change is too narrow in focus to capture the complexity of issues raised by maritally distressed couples. Although the findings are not yet published, A. Christensen and Jacobson (1995) have found that integrating acceptance along with behavior change has resulted in changes in marital adjustment that are superior to BMT focusing only on behavior change and skills training. Taken together, these findings from several investigations could indicate that helping couples gain insight or understanding of the issues and needs underlying their destructive interaction patterns is an important component for long-term maintenance of gains for some couples. At the same time, the deterioration at follow-up of more severely distressed couples treated with EFT raises caution about its appropriateness for severely disturbed couples.

The research to date and the resulting efficacy classifications do not provide information regarding the most appropriate marital interventions for a specific couple; this is the issue confronting clinicians when assessing a particular couple. Answers to this question can be derived from matching studies in which couples with specific characteristics are provided different interventions from the same or different theoretical perspectives. At present, controlled matching studies in the marital therapy field have not been conducted. Overall, the findings indicate that when couples are randomly assigned to treatment, a sizable portion of the couples remain distressed at the end of treatment and at follow-up, regardless of the form of intervention that they have received. This might reflect the strength of treatments, or it might be that through random assignment, some couples do not receive the treatment that is optimal for them given the nature of their specific presenting problems.

\section{Couples-Based Interventions for Adult Individual Disorders}

Whereas the explicit focus of the treatments discussed earlier is to intervene in a distressed relationship, the interventions described subsequently were developed to address cognitive, emotional, and behavioral difficulties. Underlying all of the treatment strategies discussed in this section is the assumption that individuals' psychological difficulties should be conceptualized and modified within a social context, especially their family. However, among the many treatments for individual disorders that include spouses and families, there is considerable variation in terms of both the strategies used and the targets of intervention.

Our review of couple- and family-level treatments that have been submitted to controlled investigation indicated that most can be classified into one of three broad types. First, some interventions can be viewed as partner-assisted or family-assisted interventions (PFAIs). In these interventions, the partner or family is used as a surrogate therapist or coach in assisting the identified patient. PFAIs typically are developed from a cognitive-behavioral framework in which the patient has specific assignments outside of the treatment session. The partner or 
family helps and coaches the patient in conducting the assignments outside of the therapy session. For example, a partner might accompany an agoraphobic individual on exposure outings for part of the therapy as a means of offering support and reinforcement for adherence to the treatment protocol. In pure PFAIs, the marital or family relationships are used to support the treatment plan, but these relationships are not a focus of the intervention.

Typically, the inclusion of the partner in this capacity has evolved as a means of enhancing the benefits of an intervention with previously demonstrated efficacy (e.g., exposure). Therefore, if a non-PFAI format has been found to be efficacious in previous investigations, we classify a PFAI as efficacious only if it is found to be superior to the original, non-PFAI format. However, if the literature indicated that a PFAI was equivalent (but not superior) to the already-established non-PFAI format, the PFAI was regarded as evidence supporting the original intervention's "effectiveness," because the evidence suggests that its format can be modified to include the participation of the partner, if necessary or preferred, without a decrease in benefit.

A second way of involving a partner or family in an individual's treatment is through the use of a disorder-specific couple or family intervention. A PFAI does not focus on the couple's or family's relationship, but a disorder-specific partner or family intervention does so by focusing on the ways in which a couple or family interacts or addresses situations related to the individual's disorder that might contribute to the maintenance or exacerbation of the disorder. As such, these interventions target the couple's or family's relationships, but only as they appear to directly influence either the disorder or its treatment. For example, a therapist might note how a partner's excuses for an alcoholic spouse help to maintain the spouse's drinking and, therefore, ask the couple to discuss how they will respond to the outside world when the alcoholic cannot go to work.

In contrast, general couples or family therapy is the third intervention that potentially can be used with individual adult disorders. In these instances, couples therapy, as described in the section on treatment of marital distress, is used with the intent of assisting the treatment of an individual's disorder (if the relationship is distressed as well, the intervention also typically has the goal of alleviating marital distress as a central part of the treatment). Such interventions often follow from the logic that the functioning of the couple or family contributes in a broad sense to the development or maintenance of individual symptoms. For example, a distressed marital relationship can be viewed as a broad stressor that will exacerbate or precipitate a wide variety of individual disorders.

Although these three types of interventions are described as discrete categories of treatment, in many instances they do not appear in pure form. For example, a treatment might largely be a PFAI, but the therapist might teach the couple communication skills so that they can more successfully discuss and carry out their homework assignments. In addition, a complete treatment package might involve any combination of discrete components. In the sections that follow, individual disorders are addressed for which there are data bearing on the efficacy of marital and family interventions for assisting in alleviating individual distress using these categories of interventions. The disorders addressed are obsessive-compulsive disorder (OCD), agorapho- bia, depression, sexual dysfunctions, alcohol abuse and dependence, and schizophrenia.

\section{Obsessive-Compulsive Disorder}

The involvement of the partner or other family member in the treatment of OCD has been evaluated as a means of improving the efficacy of commonly used behavioral interventions, particularly exposure and response prevention. Such interventions, used without the assistance of the partner, have previously demonstrated efficacy (see the DeRubeis \& Crits-Cristoph, 1998, review in this issue for a detailed discussion of the EST status of exposure for $\mathrm{OCD}$ ). Without addressing relationship issues, it has been hypothesized that including a partner or family member as a cotherapist in exposure treatment might enhance the quantity and quality of the patient's home practice sessions, during which the patient is instructed to expose himself or herself to feared stimuli and resist the urge to engage in compulsive behaviors as a means of reducing anxiety. Thus, the involvement of a significant other in the behavioral treatment of OCD has thus far reflected the PFAI approach that focuses on the disorder without attributing a functional role to marital or family functioning. To date, both partner- and family-assisted interventions have been tested. Table 2 provides more detailed information about the studies discussed subsequently. In determining the efficacy status of treatments for OCD and agoraphobia (which follows ), we relied on measures focusing directly on the experience of anxiety and compulsive behavior, including self-reports, therapist ratings, and behavioral tests.

\section{Partner-Assisted Exposure}

Two methodologically similar studies conducted by Emmelkamp and colleagues (Emmelkamp, de Haan, \& Hoodguin, 1990; Emmelkamp \& de Lange, 1983) compared outpatient treatments consisting of exposure in vivo and response prevention implemented either with or without the involvement of the patient's partner (detailed in Emmelkamp, 1982). In the partnerassisted condition, spouses were instructed to be present during homework sessions, to encourage the patient to confront distressing stimuli, and to withhold reassurance if the patient asked for it during exposure practices.

Efficacy status. In the first of these studies, which included 6 patients per treatment condition, Ernmelkamp and de Lange (1983) found the partner-assisted version to produce significantly better results at posttest on subjective and therapist-rated measures of anxiety-discomfort, self-reported general life adjustment, and independent ratings of depression. In a later study that included 25 patients per group, Emmelkamp et al. (1990) found no significant differences between the partner-assisted and nonassisted treatments at posttest. In addition, it was found that the treatments were equally effective regardless of the patient's initial level of marital distress, although those with initially high levels of marital distress showed significantly greater improvements in marital adjustment after treatment. Taken together, these studies do not provide sufficient empirical support to classify partner-assisted exposure for $\mathrm{OCD}$ as an efficacious intervention, because the bulk of the evidence does not demonstrate that it is superior to the nonassisted format.

Follow-up results. In both of the studies just described, 
Table 2

Empirical Status of Psychological Interventions for the Treatment of Anxiety Disorders

\begin{tabular}{|c|c|c|c|}
\hline Treatment & Study & Treatment conditions & Major results ${ }^{\mathrm{a}}$ \\
\hline \multicolumn{4}{|c|}{ Possibly efficacious treatments } \\
\hline $\begin{array}{l}\text { Family-assisted exposure } \\
\text { for OCD }\end{array}$ & Mehta (1990) & $\begin{array}{l}\text { 1. Family-assisted exposure }(n=15) \\
\text { 2. Nonassisted exposure }(n=15)\end{array}$ & $1>2$ \\
\hline CBT for agoraphobia & Barlow et al. (1984) & $\begin{array}{l}\text { 1. Partner-assisted CBT }(n=14) \\
\text { 2. Nonassisted CBT }(n=14)\end{array}$ & $1>2$ \\
\hline $\begin{array}{l}\text { PAE + couple communication } \\
\text { training for agoraphobia }\end{array}$ & Arnow et al. (1985) & $\begin{array}{l}\text { 1. } \mathrm{PAE}+\text { couples communication training }(n=12) \\
\text { 2. } \mathrm{PAE}+\text { couples relaxation training }(n=12)\end{array}$ & $1>2$ \\
\hline \multirow[t]{5}{*}{ PAE for agoraphobia } & Cobb et al. (1984) & $\begin{array}{l}\text { 1. PAE }(n=9) \\
\text { 2. Nonassisted exposure }(n=10)\end{array}$ & $1=2$ \\
\hline & Emmelkamp et al. (1992) & $\begin{array}{l}\text { 1. PAE }(n=30) \\
\text { 2. Nonassisted exposure }(n=30)\end{array}$ & $1=2$ \\
\hline & Hand et al. (1986) & $\begin{array}{l}\text { 1. PAE }(n=19) \\
\text { 2. Nonassisted exposure }(n=19)\end{array}$ & $1=2$ \\
\hline & Jannoun et al. (1980) & $\begin{array}{l}\text { 1. PAE }(n=14) \\
\text { 2. Partner-assisted problem solving }(n=14)\end{array}$ & $1>2$ \\
\hline & Oatley \& Hodgson (1987) & $\begin{array}{l}\text { 1. PAE }(n=15) \\
\text { 2. Friend-assisted exposure }(n=15)\end{array}$ & $1=2$ \\
\hline \multirow[t]{2}{*}{ PAE for OCD } & Emmelkamp \& de Lange (1983) & $\begin{array}{l}\text { 1. PAE }(n=6) \\
\text { 2. Nonassisted exposure }(n=6)\end{array}$ & $1>2$ \\
\hline & Emmelkamp et al. (1990) & $\begin{array}{l}\text { 1. PAE }(n=25) \\
\text { 2. Nonassisted exposure }(n=25)\end{array}$ & $1=2$ \\
\hline
\end{tabular}

Note. $\quad \mathrm{OCD}=$ obsessive-compulsive disorder $\mathrm{CBT}=$ cognitive-behavioral therapy; $\mathrm{PAE}=$ partner-assisted exposure.

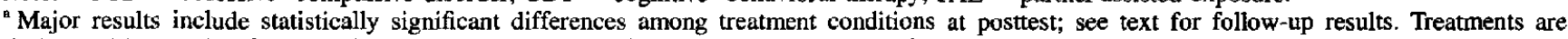
designated by number from previous column (e.g., $1>2$ indicates that Treatment 1 is statistically superior to Treatment 2 in improving symptoms of the disorder at posttest).

there were no significant differences between the partner-assisted and nonassisted groups at 1-month follow-up.

Effectiveness. The fact that the inclusion of the partner in the exposure procedures is at least as beneficial as implementing them without the partner suggests that the partner-assisted format may be a viable alternative modality.

\section{Family-Assisted Exposure}

Mehta (1990) used relaxation training in conjunction with exposure and response prevention in his evaluation of familyassisted treatment. In this study, one family member was chosen to participate in the role of cotherapist and was instructed to be present during homework practices, participate in response prevention, supervise relaxation therapy, and support the patient when he or she was depressed or anxious.

Efficacy status. Family-assisted treatment was shown to be significantly better than treatment without a family member on subjective measures of anxiety, depression, obsessions, and adjustment to family interaction and occupational functioning. There were 15 patients in each condition; in the family-assisted group, patients were assisted by parents $(n=7)$, spouses $(n=$ 6 ), or children $(n=2)$. Given these results, this intervention meets criteria for a possibly efficacious intervention.

Follow-up results. The superiority of the family-assisted version was maintained at 1-month follow-up.
Effectiveness. The Mehta (1990) study raises at least two issues regarding the effectiveness of family-assisted exposure for OCD. First, it provides evidence to support the implementation of traditional behavioral interventions in an alternate (family-assisted) format. Second, because this study was conducted in India, it raises the question of whether cultural factors moderate the effects of involving the family in treatment. Replication of the study in other countries would be helpful in evaluating whether this intervention can be expected to benefit OCD patients regardless of cultural background.

\section{Conclusions}

Taken together, the preceding studies suggest that involving a partner or family member in the exposure treatment of $O C D$ is at least as effective as treating the patient without such assistance. The fact that treatment can be successfully implemented in this way may be especially important in cases in which the patient requires the reinforcement of a significant other in the home environment to follow through with the treatment protocol. Whereas only the family-assisted format currently qualifies for possibly efficacious status, 6 of the 15 OCD patients in Mehta's (1990) family-assisted condition were aided by their spouses. As such, the beneficial effects of family-assisted treatment may have less to do with who provides assistance and more to do with other differences between this study and those of 
Emmelkamp and colleagues (1990; e.g., cultural differences). However, it is also noteworthy that the family members in the Mehta study were instructed to provide emotional support to the patients, whereas the partners in the Emmelkamp studies were instructed to withhold support. Thus, the question of which family member acts as an assistant to the therapy may be less important than the role that this assistant is asked to play.

\section{Agoraphobia}

In its original, nonassisted format, exposure therapy has been shown to be the most efficacious treatment for agoraphobia (see DeRubeis \& Crits-Cristoph, 1998, for a detailed discussion of the EST status of exposure for agoraphobia). To date, three interventions have been designed with the goal of enhancing the efficacy of exposure for agoraphobia by involving the partner in some way (see Table 2 for details of the studies). These interventions differ, however, in terms of the extent to which relationship issues thought to impede treatment gains were addressed. Two different approaches to couples' treatment of agoraphobia have been evaluated: (a) partner-assisted interventions and (b) disorder-specific couple interventions.

\section{Partner-Assisted Exposure}

First introduced by Mathews and colleagues (Mathews, Gelder, \& Johnston, 1981; Mathews, Teasdale, Munby, Johnston, \& Shaw, 1977), this intervention involves graded exposure practice conducted in the patient's home environment, with the spouse actively involved in helping to plan and carry out hierarchical homework assignments. The spouse is instructed to reinforce all practice attempts with attention and praise. As with the partner- and family-assisted interventions for $\mathrm{OCD}$, involvement of the partner is expected to facilitate more exposure experiences and decrease avoidance behaviors. Neither cognitive techniques nor relationship-focused interventions are included in this treatment, which is best characterized as a pure PFAI.

Efficacy status. Partner-assisted exposure has been compared with nonassisted exposure therapy (Cobb, Mathews, Childs-Clarke, \& Blowers, 1984; Emmelkamp et al., 1992), group exposure therapy (Hand, Angenendt, Fischer, \& Wilke, 1986), and friend-assisted exposure (Oatley \& Hodgson, 1987). In all of these studies, partner-assisted exposure was equivalent to, but not superior to, the comparison treatment. In addition, it has been shown that partner-assisted exposure is superior to partner-assisted problem solving (Jannoun, Munby, Catalan, \& Gelder, 1980; see Table 2 for a summary of the results from these studies).

When the criteria described previously for partner-assisted interventions are applied, the bulk of the evidence does not support recognition of partner-assisted exposure for agoraphobia as efficacious. Although the treatment works as well as other forms of exposure, the addition of the partner does not appear to enhance the benefit that would be expected from a nonassisted format. Similarly, the results of the Jannoun et al. (1980) study are best interpreted as support for the efficacy of exposure over problem solving; the design of the study does not permit a clear conclusion regarding the benefit of including the partner.

Follow-up results. In the Jannoun et al. (1980) study, the superiority of partner-assisted exposure was maintained at 3- month follow-up, but there were no significant differences between the treatment conditions 6 months after the end of treatment.

Effectiveness. The evidence to date indicates that involving the partner in exposure therapy for agoraphobia is at least as beneficial as conducting the treatment in a nonassisted manner. However, partner-assisted exposure has not yet been shown to be superior to other exposure formats (e.g., group and friend assisted). At present, it appears that a number of formats are available for implementing exposure therapy and that these formats are equally effective. Because no empirical studies have examined the circumstances under which one format might be superior to another, the decision about which to use currently rests on clinical judgment.

\section{Partner-Assisted Cognitive-Behavioral Treatment}

Expanding on prior work, Barlow and Waddell (1985) described a group treatment program for couples that views the relationship as an environmental context that may maintain phobic symptoms through reinforcement of avoidance and failure to positively reward anxiety-reducing behaviors. The treatment involves graduated exposure with panic management techniques and training in cognitive skills (e.g., how to use coping selfstatements) designed to prevent cognitive avoidance of fear. Partners are taught to act as coaches, reinforcing the patient for progress and assisting with the use of coping self-statements during exposure practice. In addition, therapy is used to foster more adaptive communication between the partners if poor communication or other relationship issues interfere with progress. Relationship issues are addressed only to the extent that they interfere with treatment goals, and no explicit relationship skills training is conducted. Although some prior reviews (Dewey \& Hunsley, 1990; Emmelkamp \& Gerlsma, 1994) have not distinguished this intervention from that discussed earlier, the inclusion of a cognitive component and the explicit attention to relationship factors in this treatment warrant a separate evaluation for purposes of determining EST status. In fact, unlike the strictly PFAI approach described earlier, this intervention has features consistent with both the PFAI and disorder-specific partner or family intervention categories.

Efficacy status. In a single study that has been reported in multiple articles, Barlow and colleagues (Barlow, O'Brien, \& Last, 1984; Cerny, Barlow, Craske, \& Himadi, 1987; Craske, Burton, \& Barlow, 1989; Himadi, Cerny, Barlow, Cohen, \& O'Brien, 1986) compared this partner-assisted cognitive-behavioral group treatment ( $n=14$ ) with a similar treatment that neither involved the partner nor addressed relationship issues $(n=14)$. They found that the treatments did not differ significantly on clinicians' ratings or subjective measures at posttest, although patients in the partner-assisted group had significantly less work interference immediately after treatment. In addition to comparing between-groups differences, however, the investigators divided the patients into two a priori categories, treatment responders and nonresponders, based on whether they showed at least $20 \%$ improvement on at least three of five subjective and behavioral measures. On the basis of these criteria, $85 \%$ of the patients in the partner-assisted group and $50 \%$ of the patients in the nonassisted group were classified as treatment responders; this difference was statistically significant. Whereas neither ob- 
jectively measured marital communication nor self-reported marital satisfaction predicted treatment responsiveness, patients who reported more frequent communication with their spouses before treatment were more likely to be classified as treatment responders. Although the outcome data from this study are mixed, it seems appropriate to classify this partner-assisted intervention as a possibly efficacious treatment.

Follow-up results. Despite only one significant difference between the treatment groups at posttest, the partner-assisted group was rated significantly less symptomatic and had significantly less work interference at 12- and 24-month follow-ups and had significantly lower scores on subjective measures of anxiety at 12-month follow-up. In addition, there were significantly more treatment responders in the partner-assisted group at 2-year follow-up. Interpretation of these findings should be qualified, however, by the fact that follow-up results are based on the data of the original 28 participants in combination with an additional 14 participants nonrandomly assigned to the partnerassisted condition.

\section{Partner-Assisted Exposure Plus Couple Communication Training}

Arnow, Taylor, Agras, and Telch (1985) expanded on the partner-assisted exposure treatments just described by adding a communication skills training component that focused on constructive speaking, empathic listening, and conflict resolution (Jacobson \& Margolin, 1979; R. B. Stuart, 1980). These skills were taught as a means of addressing marital issues that have the potential to interfere with treatment gains, as well as to minimize spouse behaviors that may unwittingly maintain or exacerbate phobic symptoms by impeding the development of autonomy in the patient. Because it focuses communication skills training exclusively on relationship issues that could interfere with treatment without attention to broader relationship difficulties, the communication training component of this treatment is a disorder-specific couple intervention.

Efficacy status. Couples receiving partner-assisted exposure along with eight sessions of communication training were compared with couples receiving the same exposure therapy along with eight sessions of couple relaxation training. At posttest, patients in the exposure plus communication training group had significantly lower subjective anxiety and more unaccompanied excursions than the exposure plus relaxation couples. As anticipated, couples in the communication group had significantly more positive and fewer negative communication behaviors after treatment. Only $25 \%$ of the couples in this sample were maritally distressed at pretest, and there was little change in marital satisfaction for either of the treatment groups. The results of this study suggest that teaching couples to discuss and solve problems surrounding how they handle agoraphobic symptoms can improve on the effectiveness of exposure. As such, the addition of couples communication training to partner-assisted exposure qualifies as possibly efficacious.

Follow-up results. The preceding between-groups differences were maintained at 8-month follow-up.

\section{Conclusions}

In summary, this review indicates that exposure interventions for agoraphobia may show enhanced benefit from involvement of the partner in some capacity. It is notable that both of the possibly efficacious treatments reviewed here have been shown to be beneficial even when there is no overt relationship distress. This suggests that interventions targeted at relationship functioning focal to the individual's disorder may be useful even when there are no obvious relationship difficulties. To help clarify when the inclusion of the partner in this way is most likely to enhance efficacy, it is recommended that future investigators attempt to assess theoretically relevant relationship variables in addition to global adjustment that might moderate or mediate outcome (e.g., negative-positive reciprocity in communication and support for autonomy).

\section{Depression}

In contrast to the interventions for agoraphobia and OCD, which do not address broad relationship issues, partner-familylevel treatments for depression have targeted general relationship functioning as a means of eliminating depressive symptoms. That is, couples with a depressed partner have been treated within the context of existing theoretical approaches to assisting maritally distressed couples (i.e., BMT and conjoint interpersonal therapy for depression ). In addition to evaluating the efficacy of using general couples therapy for depression, investigators typically have attempted to assess the effects of the treatment on relationship functioning. In determining a treatment's efficacy status, changes in depression were used as the criterion of central concern; however, changes in marital adjustment speak to the treatment's effectiveness as an intervention for marital distress. To date, only three well-controlled studies have been conducted with the explicit purpose of treating depression with marital therapy, although additional investigators have used data from existing marital treatment outcome studies to learn more about the role of depression within maritally distressed couples. (For a fuller discussion of the relationship between depression and marital distress, see Beach, Smith, \& Fincham, 1994; Gotlib \& Beach, 1995; Prince \& Jacobson, 1995.) Details of these three investigations are presented in Table 3.

\section{Behavioral Marital Therapy}

Efficacy status. Two investigations have evaluated the efficacy of implementing BMT with couples in which the wife is clinically depressed (Jacobson, Dobson, Fruzzetti, Schmaling, \& Salusky, 1991; O'Leary \& Beach, 1990). O'Leary and Beach assigned 36 maritally distressed couples in which the wife met criteria of the Diagnostic and Statistical Manual of Mental Disorders (third edition; DSM-III; American Psychiatric Association, 1980) for major depression or dysthymia to (a) BMT, (b) individual CT for the wife, or (c) a waiting list condition. In this investigation, couples were seeking assistance for both depression and marital difficulty. The findings indicated that, at posttest, each of the two treatment conditions was more efficacious than the waiting list condition in alleviating depression, but there were no significant differences between BMT and $\mathrm{CT}$.

Jacobson et al. (1991) conducted a somewhat similar investigation with 60 couples in which the wives had been diagnosed with major depression. In contrast to those treated by O'Leary and Beach (1990), the couples in this study were not selected 
Table 3

Empirical Status of Psychological Interventions for the Treatment of Depression

\begin{tabular}{|c|c|c|c|}
\hline $\begin{array}{l}\text { Possibly } \\
\text { efficacious } \\
\text { treatment }\end{array}$ & Study & Treatment conditions & Major results $^{\mathrm{n}}$ \\
\hline \multirow[t]{2}{*}{ BMT } & Jacobson et al. (1991) & $\begin{array}{l}\text { 1. BMT }(n=19) \\
\text { 2. Individual cognitive therapy }(n=20) \\
\text { 3. BMT }+ \text { individual cognitive therapy }(n=21)\end{array}$ & $\begin{array}{c}2>1 ; 1=3 \text { for non-maritally distressed } \\
1=2=3 \text { for maritally distressed }\end{array}$ \\
\hline & O'Leary \& Beach (1990) & $\begin{array}{l}\text { 1. BMT }(n=12) \\
\text { 2. Individual cognitive therapy }(n=12) \\
\text { 3. Wait list }(n=12)\end{array}$ & $1=2>3$ \\
\hline
\end{tabular}

Note. $\quad$ BMT $=$ behavioral marital therapy.

${ }^{\text {a }}$ Major results include statistically significant differences among treatment conditions at posttest; see text for follow-up results. Treatments are designated by number from previous column (e.g., $1>2$ indicates that Treatment 1 is statistically superior to Treatment 2 in improving depression at posttest). See text for effects of these treatments on marital adjustment.

on the basis of their level of marital distress; as a result, there were nondistressed as well as distressed couples in this sample. Moreover, none of the couples were seeking treatment for relationship problems, as were the couples in the preceding study. The couples were assigned to (a) BMT, (b) CT, or (c) a treatment combining BMT and CT. In terms of alleviating depression at posttest, the findings indicated that BMT was significantly less effective than CT for couples who were not maritally distressed; however, the treatments were comparable when the couples were maritally distressed. Contrary to expectation, the combined treatment was no more effective than either component condition in alleviating depression, regardless of level of distress.

In summary, one study has demonstrated that BMT is more effective than a waiting list condition in alleviating depression for wives who are also experiencing relationship distress. In addition, both of the studies conducted to date have found that BMT is equivalent to CT in alleviating depression among maritally distressed couples, although the sample sizes are smaller than those specified in Chambless and Hollon's (1998) criteria. Thus, as a result of the limited sample sizes, BMT should be viewed as a possibly efficacious treatment for depression of women in maritally distressed couples.

Follow-up results. Both Beach and O'Leary (1992) and Jacobson, Fruzzetti, Dobson, Whisman, and Hops (1993) found that BMT and CT were equivalent in altering depression at follow-up. More specifically, Beach and O'Leary found the two treatments to be equally efficacious at 1-year follow-up. Similarly, in the Jacobson et al. study, 6- and 12-month follow-ups indicated that there were no significant differences in depression relapse rates across treatment conditions.

Clinical significance. The findings from both investigations demonstrate that BMT has a significant clinical impact in alleviating depression for wives when the couple is maritally distressed. For example, O'Leary and Beach (1990) found no significant differences between BMT and CT; overall, approximately three fourths of the wives receiving treatment no longer met criteria for depression at posttest. Similar to the mean differences obtained by Jacobson et al. (1991), evaluations of clinically significant changes in depression indicated that wives receiving CT responded well to treatment, regardless of initial level of marital distress (i.e., $71 \%$ and $85 \%$ recovery rates from depression for maritally distressed and nondistressed couples, respectively), whereas couples receiving BMT varied considerably depending on level of marital distress (i.e., $88 \%$ and $55 \%$ recovery rates for maritally distressed and nondistressed couples, respectively).

Effectiveness. The findings from the studies just described suggest that BMT is a fruitful treatment for alleviating depression in a maritally distressed couple. An additional area of great importance is the impact of BMT and CT in altering marital distress among these same couples, along with the interplay between changes in depression and marital adjustment. O'Leary and Beach (1990) found that BMT was significantly more effective than CT and the waiting list condition in increasing marital adjustment at posttest. However, CT was no more effective than the no-treatment condition in altering marital adjustment. Whereas $83 \%$ of couples receiving BMT improved significantly on marital adjustment, only $25 \%$ of couples in the CT condition showed comparable changes. The superiority of BMT over CT in increasing marital adjustment was maintained at 1-year follow-up. Although there were only 12 couples per treatment condition, and this small sample size could have contributed to the lack of significant differences in depression between treatment conditions, the finding of significant differences on marital adjustment indicates that the two treatments do have some differential effects.

These initial findings would seem to favor BMT as a treatment for depressed, maritally distressed couples in that it increased marital adjustment and decreased depression. However, further analyses involving these same couples indicate that response to these two treatments is related to other important factors. O'Leary, Riso, and Beach (1990) and Beach and O'Leary (1992) provided evidence that, among maritally distressed couples in which the wife is depressed, these women respond well to CT if they report that their depression precedes their marital problems, they view their marital relationship more positively, and they primarily appear to experience cognitive symptoms of depression. However, when marital distress is reported to have preceded the depression, the marital relationship is perceived more negatively, and cognitive distortions are less pronounced, then CT is not as effective, and BMT appears to be more effective. Consistent with this conclusion, Beach and O'Leary found that, among couples receiving BMT, decreases in the wife's depression were mediated by increases in her marital adjust- 
ment. Although these findings are post hoc and require replication, they provide fruitful avenues for further investigation.

Whereas O'Leary and Beach (1990) found a pattern favoring BMT in alleviating marital distress, Jacobson et al.'s (1991) overall findings do not seem to bear this out. However, all of the couples in the O'Leary and Beach study were distressed, whereas many couples in the Jacobson et al. study were not. Jacobson et al. (1993) reanalyzed their findings, focusing on couples in which both partners were maritally distressed. The sample size was too small to allow for inferential statistical comparisons, but the pattern of findings is striking and supports the results of O'Leary and Beach. Among these more maritally distressed couples, BMT led to increases in marital adjustment three times as great as those demonstrated among couples in the CT condition. Most important, in these more maritally distressed couples, $100 \%$ of the women receiving BMT recovered from depression, as compared with only $50 \%$ in the CT condition and $43 \%$ in the combined condition.

\section{Conjoint Interpersonal Psychotherapy for Depression}

As noted in DeRubeis and Crits-Cristoph (1998), interpersonal psychotherapy for depression (IPT) is a brief, individual form of psychotherapy developed from a psychodynamic perspective. Interpersonal difficulties are viewed as a central theoretical construct in IPT, as well as being the focus of intervention. It seems understandable that IPT would be expanded to a conjoint format to assist couples in which one spouse is depressed and that it views marital discord as the major problem associated with the onset or exacerbation of the depression.

Foley, Rounsaville, Weissman, Sholomskas, and Chevron (1989) conducted a pilot study (9 couples per condition) comparing individually focused IPT with a conjoint marital form of IPT (IPT-CM). Their findings were similar to those described earlier for BMT. Although both treatment conditions evidenced significant decreases from pretest to posttest on depression, there were no differences between the treatments with regard to changes in depression. However, couples receiving IPT-CM were significantly more satisfied with their relationship than were couples in which the patient received IPT. In fact, the patients receiving IPT showed no mean change in marital adjustment. In addition, whereas patients demonstrated significant increases on a measure of affectional expression when they received IPT-CM, patients receiving IPT showed a trend toward decreased affectional expression; this difference between treatment conditions also was significant. Although the small sample size and lack of replication make it inappropriate to comment on the EST status of IPT-CM, the initial findings point once again to a conjoint form of treatment that might be equal in impact to individual therapy in altering depression for maritally distressed couples and superior in improving marital adjustment. Consequently, the findings speak to the effectiveness of this intervention for alleviating marital distress among couples in which a partner is depressed.

\section{Conclusions}

O'Leary and Beach (1990) were the only investigators to compare a marital intervention with a wait list condition, and they found BMT to be superior to no treatment in alleviating depression. However, the relative efficacy of marital interventions versus individual psychotherapy for depression (either CT or IPT) is unclear as a result of the restricted power in the investigations to date. Perhaps the most intriguing pattern of findings from the preceding studies is that marital therapy (BMT and IPT-CM) might be preferable to individual psychotherapy (CT and IPT) among maritally discordant couples with a depressed wife because it leads to improvement in both depression and marital discord. In addition, the findings to date suggest that when a couple is not maritally distressed, BMT may not be the treatment of choice for alleviating depression; in such instances, CT may be more effective. Both of these tentative conclusions await replication with larger samples.

\section{Sexual Dysfunctions}

Evaluation of treatments for sexual dysfunctions may be compromised by the evident confounding among date of publication, type of treatment, and the quality of the methodology used in the various studies. Early studies of treatments such as LoPiccolo and Lobitz's (1972) and Masters and Johnson's (1970), characterized as partner-assisted interventions and disorder-specific partner interventions, used baseline data as a control rather than between-groups comparisons, rendering many of them incompatible with our EST criteria and unqualified for the purpose of establishing efficacy status. An additional confound was introduced by the increased recognition of the importance of the relational context of sexual dysfunctions. This recognition overlapped with an increase in the diagnosis of hypoactive sexual desire disorders (HSDD), a category that did not exist as such before the 1980s. As a means of addressing the contextual nature of these disorders, more comprehensive therapies were implemented, adding elements of general marital therapy to alreadyexisting partner-assisted and disorder-specific interventions. Because the more comprehensive therapies have been studied more recently and according to recent experimental design expectations, evidence for the efficacy of comprehensive treatments of HSDD is more likely to exist than for the early treatments of orgasmic disorders developed by Masters and Johnson and LoPiccolo and Lobitz. In other words, the efficacy status reported in the following section may be an underestimate of the persuasiveness of the evidence, especially regarding early treatments for sexual dysfunctions (see other reviews by Beck, 1995; Emmelkamp, 1994; Hawton, 1995; LoPiccolo \& Stock, 1986).

We identified four treatments for which there are studies that meet Chambless and Hollon's (1998) criteria, all for female sexual dysfunctions: (a) two early-developed (pre-1980s) treatments targeting primary (lifelong) and secondary (situational) orgasmic disorder and (b) two later-developed (post-mid1980s) combined treatments targeting mixed secondary orgasmic and desire problems and HSDD. A consistent evaluation of outcome was facilitated by the fact that most studies in the area use outcome indexes that include focal measures of the target complaint (e.g., the Sexual Interaction Inventory [LoPiccolo \& Steger, 1974]).

We present the diagnostic categories of orgasmic disorders and HSDD as if they are discrete entities because of the way in which the existing empirical literature is organized. We should note, however, that $D S M$ (revised third edition [DSMIII-R; American Psychiatric Association, 1987] and fourth edi- 
tion [DSM-IV; American Psychiatric Association, 1994]) categories of sexual dysfunctions have been criticized for lacking empirical validation and conceptual clarity (Rosen \& Leiblum, 1995); desire, arousal, and orgasmic disorders often coexist (Segraves \& Segraves, 1991). There are additional problems with conceptualizing sexual dysfunctions as discrete entities because comorbidity exists not only within individuals but between partners. LoPiccolo and Stock (1986) estimated that 45\% of sexually dysfunctional persons have sexually dysfunctional spouses. Nonetheless, while recognizing the comorbidity of these conditions within and between partners, we discuss the various treatment strategies for specific sexual dysfunctions as they appear in the empirical literature. Details of the studies that follow are presented in Table 4.

\section{Sexual Skills Training for Primary Female Orgasmic Disorders}

An intervention, first introduced by LoPiccolo and Lobitz (1972), based on improving sexual skills through directed masturbation training is often considered the treatment of choice for lifelong orgasmic disorder (Rosen \& Leiblum, 1995), especially for clients motivated to achieve orgasm via sexual activities with their partners (Leiblum \& Ersner-Hershfield, 1977). The treatment protocol is clear and replicable, involving nine sequential steps that include education and self-exploration, directed masturbation, sexual fantasy and imagery, and sensate focus (first individually and then with a partner). In the final step, women are coached on sharing effective techniques of masturbation with their partners (LoPiccolo \& Stock, 1986). Whereas guided masturbation is designed to provide the woman with the reinforcing experience of orgasm, the partner's assistance is designed to facilitate progress throughout the program. Thus, this treatment is best thought of as a partner-assisted intervention.

Efficacy status. Partner-assisted sexual skills training (SST) for primary (lifelong) orgasmic disorder has been compared with minimal treatment (Riley \& Riley, 1978) and with nonassisted SST (Ersner-Hershfield \& Kopel, 1979). Riley and Riley (1978) compared two types of partner-assisted interventions for primary orgasmic disorders: (a) SST and (b) a combined sensate focus and supportive treatment (presented as a minimal-treatment control group). Results indicated impressive differences in improvement rates between the two groups: At the end of the 12-week treatment, $90 \%$ of the experimental and only $53 \%$ of the comparison control clients were able to achieve orgasm by any means. Moreover, $85 \%$ of the experimental group versus $47 \%$ of the comparison group were coitally orgasmic on at least $75 \%$ of occasions. The differences between improvement rates in the two conditions were statistically significant.

Challenging the efficacy of women-alone SST, Ersner-Hershfield and Kopel (1979) conducted SST in a group format comparing groups of women only and groups of couples. The study had insufficient power $(n=22)$ to detect moderate differences between two active treatments. However, one intriguing finding is nevertheless worth noting: Although there were no significant group differences in female orgasmic responses, clients in the women-only group reported significantly more male erectile dysfunction. This finding augments other reports of negative consequences of treating married (or cohabiting) women in isolation from their partners (e.g., Schneidman \& McGuire, 1976) and provides supportive evidence for the partner-assisted format of SST. On the basis of the superiority of SST in the Riley and Riley (1978) investigation and the limited power in the Ersner-Hershfield and Kopel (1979) investigation, SST for primary female orgasmic disorders is classified as possibly efficacious and specific.

Follow-up results. In the Riley and Riley (1978) study, the superiority of partner-assisted SST over the minimal-treatment control was maintained at 12-month follow-up. In Ersner-Hershfield and Kopel's (1979) study, the negative consequences of

Table 4

Empirical Status of Psychological Interventions for the Treatment of Sexual Dysfunctions

\begin{tabular}{|c|c|c|c|}
\hline $\begin{array}{l}\text { Possibly efficacious } \\
\text { and specific treatment }\end{array}$ & Study & Treatment conditions & $\begin{array}{l}\text { Major } \\
\text { results }^{\mathrm{a}}\end{array}$ \\
\hline \multirow[t]{2}{*}{$\begin{array}{l}\text { SST for primary female orgasmic } \\
\text { disorder }\end{array}$} & Riley \& Riley (1978) & $\begin{array}{l}\text { 1. SST }(n=20) \\
\text { 2. Minimum treatment control }(n=15)\end{array}$ & $1>2$ \\
\hline & Ersner-Hershfield \& Kopel (1979) & $\begin{array}{l}\text { 1. Women-only group SST }(n=12) \\
\text { 2. Couple group SST }(n=10)\end{array}$ & $2 \geq 1$ \\
\hline $\begin{array}{l}\text { M\&J for female orgasmic } \\
\text { disorders }\end{array}$ & Everaerd \& Dekker (1981) & $\begin{array}{l}\text { 1. } \mathrm{M} \& \mathrm{~J}(n=25) \\
\text { 2. Communication-problem solving }(n=20)\end{array}$ & $1>2$ \\
\hline $\begin{array}{l}\text { BMT }+ \text { M\&J for mixed female } \\
\text { sexual dysfunctions }\end{array}$ & Zimmer (1987) & $\begin{array}{l}\text { 1. Communication-problem solving }+\mathrm{M} \& \mathrm{~J}(n=10) \\
\text { 2. Attention-placebo }+\mathrm{M} \& \mathrm{~J}(n=9) \\
\text { 3. Wait list }(n=9)\end{array}$ & $\begin{array}{l}1>3 \\
2 \geq 3 \\
1 \geq 2\end{array}$ \\
\hline $\begin{array}{l}\text { Marital + OCT for hypoactive } \\
\text { sexual desire }\end{array}$ & Hurlbert et al. (1993) & $\begin{array}{l}\text { 1. Couple group behavior exchange }+ \text { OCT }(n=19) \\
\text { 2. Women-only group behavior exchange }+ \text { OCT }(n=19) \\
\text { 3. Wait list }(n=19)\end{array}$ & $\begin{array}{l}1 \geq 2 \\
1>3\end{array}$ \\
\hline
\end{tabular}

Note. $\quad$ SST $=$ sexual skill training; $\mathrm{M} \& \mathrm{~J}=$ Masters and Johnson; $\mathrm{BMT}=$ behavioral marital therapy; OCT $=$ orgasm consistency training.

- Major results include statistically significant differences among treatment conditions at posttest; see text for follow-up results. Treatments are designated by number from previous column (e.g., $1>2$ indicates that Treatment 1 is statistically superior to Treatment 2 in improving sexual functioning at posttest, and $1 \geq 2$ indicates that Treatment 1 is statistically superior to Treatment 2 on some but not all main dependent variables). 
treating women without their partners (i.e., increased male erectile dysfunction ) were maintained at the 5- and 10-week followup measurement points. Furthermore, women in the couple group reported more satisfaction regarding frequency of orgasm, and both partners reported higher levels of pleasure in their couple activities than the women-only group at both 5 and 10-week follow-up measurement points.

Clinical significance. Ersner-Hershfield and Kopel (1979) reported that $91 \%$ of the patients in both groups achieved orgasm via self-stimulation at posttest, and $82 \%$ achieved orgasm at 10 -week follow-up. The rates of male erectile dysfunction following the partner-assisted format in the couple group were within the normal range (10\%).

Effectiveness. The evidence to date indicates that the partner-assisted format of SST for female primary (lifelong) orgasmic disorder is feasible and may be beneficial to both partners. According to Ersner-Hershfield and Kopel (1979), consumer satisfaction was higher in the couple group. Low attrition rates in both studies of partner-assisted SST indicate patient acceptance of the treatment. Furthermore, several effectiveness studies have found that a 15 -session weekly treatment format is as effective as a 15-session daily treatment protocol (Heiman \& LoPiccolo, 1983) and that cotherapy is not superior to a single (male or female) therapist format (LoPiccolo, Heiman, Hogan, \& Roberts, 1985). To date, there is no clear evidence that the efficacy status of SST can be generalized to the treatment of secondary (situational) female orgasmic disorders.

\section{Masters and Johnson's Program for Primary and Secondary Female Orgasmic Disorders}

Masters and Johnson's (1970) treatment includes two components: partner-assisted directed practice and disorder-specific couple-level counseling. Whereas in the former the partner serves as a coach, in the latter the therapist helps the partners discuss and resolve specific difficulties and misunderstandings they encounter in their sexual interactions and in interactions around sexual issues. At the heart of the treatment is the couple's gradual progression from nongenital mutual pleasuring to sexual intercourse. Treatment begins with a complete banning of intercourse and genital stimulation, together with providing homework instructions (termed sensate focus) for giving mutual pleasure (e.g., alternate giving and receiving of caresses while avoiding specifically sexual areas). As the couple progresses, therapy continues with "genital sensate focus" and a number of specific homework exercises designed to coach couples on giving and receiving caresses along a graded sequence culminating with intercourse (Mathews, Whitehead, \& Kellet, 1983).

Efficacy status. Everaerd and Dekker (1981) assigned 45 couples ( 10 with primary and 35 with secondary orgasmic disorders) either to an adaptation of Masters and Johnson's (1970) sex therapy or to a communication therapy (i.e., general marital intervention). Both treatments were conducted by a male-female cotherapy team who followed treatment manuals. Whereas communication therapy was designed to improve the overall quality of the couples' relationship, sex therapy was designed to improve partners' sexual skills and alter specific sexual interactions that might hinder orgasm (e.g., when partners inquire about each other's state of arousal or exert pressure for improved performance). One of the many strengths of the study was the inclusion of target-specific measures to capture the quality of sexual interaction, as well as the frequency of orgasm. The investigators found a main effect favoring Masters and Johnson's sex therapy over communication therapy on the female orgasmic factor. Everaerd and Dekker's design and findings support the classification of the Masters and Johnson's treatment for (primary and secondary) orgasmic disorders as possibly efficacious and specific.

Follow-up results. At 6-month follow-up, the efficacy of Masters and Johnson's sex therapy for women was maintained. In addition, not only was this therapy more efficacious than communication therapy in improving men's satisfaction with sexual interaction, but communication therapy actually had a negative effect on men's satisfaction with sexual interaction.

Effectiveness. Mathews et al. (1976) conducted a randomized component analysis comparing (a) partner-assisted directed practice, (b) disorder-specific couple counseling, and (c) a treatment that combined both components. Although the investigators did not find statistically significant group effects, differences in improvement rates indicated that the combination of both components of Masters and Johnson's program tended to work better than each component alone. Subsequent investigations of this program have used the combined partner-assisted and disorder-specific treatment as the format of choice.

The Masters and Johnson treatment program has been clearly articulated and widely practiced. Over the past three decades, investigators have collected data on improvement rates for the various sexual dysfunctions, using patients' own baseline data as a control ( see Hawton, 1995, for a review). These investigators, however, have also suggested some factors that may restrict the applicability of this treatment. These factors pertain mainly to the range of the targeted sexual dysfunctions and the quality of the couple's relationship and the spouses' compliance with treatment.

There is mixed evidence regarding the patient populations to which one can generalize the efficacy status obtained for female orgasmic disorders. Two studies indicate that the efficacy status of Masters and Johnson's treatment may not generalize to a sample mixed with regard to gender and dysfunction (Crowe, Gillan, \& Golombok, 1981) or to a sample of couples with male erectile dysfunction (Ansari, 1976). Crowe et al. assigned couples to Masters and Johnson's sex therapy or to relaxation and marital communication training and found that only 1 of 20 outcome measures distinguished between the groups. In Ansari's (1976) study, patients (all couples with male erectile dysfunction ) did not fare better under Masters and Johnson's program than they did in a no-treatment control group. In fact, examination of Ansari's data indicated that the no-treatment control group had higher numbers of recovered patients than the Masters and Johnson treatment.

Better results were obtained when the sample was restricted to women with mixed dysfunction ( secondary orgasmic disorder and problems with sexual desire and arousal). Targeting this population, Zimmer (1987) found that sex therapy preceded by a placebo control (relaxation and information) was superior to a waiting list control on measures of symptom severity. Because Zimmer did not compare sex therapy alone (i.e., without the potential augmentation of the placebo control) with a waiting list condition, this finding cannot serve to establish efficacy status for Masters and Johnson's treatment for this population. 
It does suggest, however, that their treatment may be effective for a broader sample of women than the range studied by Everaerd and Dekker (1981).

Couples' functioning is another factor that may limit the beneficial effects of Masters and Johnson's treatment. On the basis of naturalistic studies examining patients' improvement rates without assigning them to experimental and control groups, Hawton and Catalan (1986) found that poorer outcomes were associated with (a) higher levels of pretreatment marital distress, (b) a history of marital separation, (c) lower motivation in male partners, and (d) couples' lack of compliance with homework. The negative correlation between marital adjustment and treatment outcome appears to be robust; this finding was replicated in several studies, including ones that used a truncated distribution of marital distress due to the exclusion of highly distressed couples (e.g., Hawton, Catalan, \& Fagg, 1991, 1992; Whitehead \& Mathews, 1986). In his review of the field, Hawton (1995) concluded that the effectiveness of Masters and Johnson's sex therapy may be restricted to a highly select sample of compliant couples who get along well and do not have drinking or other psychological problems.

\section{Behavioral Marital Therapy Plus Masters and Johnson's Treatment for Mixed (Secondary) Female Sexual Dysfunctions}

The frequent exclusion of maritally distressed couples from traditional sex therapy (Hawton, 1995) precludes the application of Masters and Johnson's treatments to many cases of HSDD and secondary orgasmic disorders (i.e., situational rather than lifelong), because couples presenting with these dysfunctions are significantly more maritally distressed than couples who receive sex therapy for other sexual dysfunctions (e.g., vaginismus or life-long orgasmic disorders; F. Stuart, Hammond, \& Pett, 1987). Because in more than half of these couples the disorder is partner specific (or relationship specific), adding a component of general marital therapy to partner-assisted and disorder-specific couple treatments is reasonable. (The only controlled study that evaluated the efficacy of general marital therapy [EFT] without any partner-assisted or disorder-specific intervention did not find the EFT treatment to be superior to a waiting list control [MacFee \& Johnson, 1995].)

Efficacy status. Zimmer (1987) hypothesized that addition of general marital therapy (BMT) should enhance the effects of sex therapy for a sample of maritally distressed couples in which the woman was diagnosed with secondary sexual dysfunctions, including orgasmic, arousal, and desire disorders. Forty-four couples were assigned to one of three groups: (a) The experimental group underwent 9 weeks of marital therapy before receiving sex therapy (12 weeks of Masters and Johnson's program); (b) the comparison group underwent a placebo control (relaxation and information) period before receiving sex therapy; and (c) the third condition was a waiting list control. The main components of the marital therapy were communication training and strategies for conflict resolution. In spite of the small sample size ( $9-10$ per group), the combined (experimental) treatment was superior to the waiting list control on all measures; it was also superior to the comparison treatment in terms of level of sexual desire, intensity of coitus, and a summary problem score but not in terms of symptom severity and level of women's pleasure. These findings suggest that a combined (sequential) BMT plus standard sex therapy intervention package is possibly efficacious for maritally distressed couples with female secondary sexual dysfunction.

Follow-up results. The pattern of results obtained at the posttreatment measurement was maintained at 3-month followup. The investigator used a meta-analytic technique to demonstrate that, at follow-up, the average couple from the combined treatment was superior to $85 \%$ of the comparison treatment group on the problem-sum score and superior to $67 \%$ on symptom severity.

Clinical significance. At the end of treatment, and in contrast to the other two groups, couples who received the combined treatment showed average rates of improvement placing them within the range of normal couples on the problem-sum score of a German-language version of LoPiccolo and Steger's (1974) Sexual Interaction Inventory.

Effectiveness. Zimmer's sample included orgasmic, arousal, and desire disorders, a mixture that is reasonable in light of the high level of comorbidity of the various secondary dysfunctions and the questionable empirical validity of the discrete $D S M-I V$ categories (Rosen \& Leiblum, 1995). Adding to the ecological validity of the study, half of the male partners in Zimmer's sample suffered from some form of sexual dysfunction. Moreover, the overall level of marital distress was equivalent to that of couples seeking treatment for marital problems: In $67 \%$ of the couples, at least one partner had seriously considered separation. However, high (although not differential) attrition rates $(36 \%)$ may limit the generalizability of Zimmer's (1987) findings. Couples who terminated their participation in the study might have been the most maritally distressed. Indeed, 13 of the 16 couples who dropped out eventually separated. According to Zimmer's post hoc analysis, couples who had lower levels of pretreatment relational equality showed fewer treatment gains. This result resembles another post hoc finding of Jacobson, Follette, and Pagel (1986), who reported that egalitarian couples benefited more from BMT.

\section{General Marital Therapy Plus Orgasm Consistency Training for Hypoactive Sexual Desire Disorders}

Two studies by Hurlbert and colleagues (Hurlbert, 1993; Hurlbert, White, Powell, \& Apt, 1993) challenged the notion that interventions designed to facilitate orgasm would help only women diagnosed with orgasmic disorders. Targeting HSDD women and their partners, Hurlbert (1993) tested the efficacy of adding orgasm-consistency training to a standard treatment that included SST and general marital therapy based on social exchange theory. The general intervention included improving the ratio of positive to negative reinforcement, enhancing couple communication skills, and teaching couples general conflict resolution skills. Orgasm consistency training includes several sequential steps for training couples in directed masturbation, followed by couple-involved exercises (e.g., sensate focus) and coital alignment techniques (see details in Eichel, Eichel, \& Kule, 1988). All treatments were conducted in groups with no more than five couples, and throughout the course of treatment therapists coached couples on how to alter sexual interactions and disorder-relevant intimate communication. The treatment 
is a combined package that includes partner-assisted, disorderspecific, and general marital interventions.

Efficacy status. Hurlbert et al. (1993) tested the specific as well as the nonspecific effects of the combined treatment. Women diagnosed with HSDD were randomly assigned to a couple-only (the combined treatment), women-only, or waiting list condition ( $n=19$ per group). At posttest assessment, the couple group was superior to the waiting list control group on all but the sexual assertiveness measure; that is, they were superior to the control group on sexual compatibility, desire, and satisfaction. Furthermore, the couple group was superior to the women-only group on two of the six measures, including sexual desire. The results of this study place this type of combined treatment for HSDD in the possibly efficacious and specific category. (The second study by Hurlbert [1993] replicated the results with a sample of military couples but could not be considered a randomized clinical trial because of a serious problem with differential attrition.)

Follow-up results. The difference between the two treatments sharpened at 6-month follow-up. The couple group was superior to the women-only group on all but the sexual assertiveness measures.

\section{Conclusions}

This review identified four possibly efficacious and specific treatments for women, but no efficacious treatments for male sexual dysfunctions. As noted in the introduction to this section, our application of EST criteria may have led to an underestimated efficacy for the less recently developed and investigated treatments. In fact, Hawton and Catalan (1986) and Hawton (1995) have suggested that the paucity of controlled studies of earlier treatments does not necessarily imply that they are not efficacious. For example, they reported an overall improvement rate of $66 \%$ for patients in the Masters and Johnson program and stated that they consider it a treatment that is now "wellestablished"' (Hawton, 1995, p. 307).

There are important questions to address regarding the treatment of sexual dysfunctions, and although definitive answers are unavailable, existing data provide some suggestions. First, should individuals with sexual dysfunctions be treated as individuals or as part of a couple? Two independent investigations found that including the spouse in treatment yielded better outcomes than treating women alone (Ersner-Hershfield \& Kopel, 1979; Hurlbert et al., 1993). Second, should the couples' overall relationships, rather than the sexual interactions, be the target of treatment? It appears that a direct focus on sexual interactions is important in treating sexual dysfunctions. When a general (emotion-focused) couples intervention was conducted without a disorder-specific intervention, it was not more effective than a no-treatment control (MacFee \& Johnson, 1995). When communication enhancement was compared with a disorder-specific intervention, the former was less effective than the latter (Everaerd \& Dekker, 1981). Third, should severe marital complaints be treated before sexual dysfunctions can be addressed? Not necessarily. Zimmer's (1987) recommendation to enhance couples' communication before initiation sex therapy has yet to be replicated, and a study too small to qualify for our inclusion criteria (Hartman \& Daly, 1983) actually favored the opposite sequence (sex therapy followed by marital communication enhancement).

Finally, despite the finding that sexual and marital problems are more closely related among men than among women (e.g., Rust, Golombok, \& Collier, 1988) and the recent increase in male complaints of HSDD (Beck, 1995), few studies of psychosocial interventions have targeted male dysfunction. The paucity of efficacy data, as well as recent advances in the diagnosis and treatment of erectile dysfunction made by medical specialists (especially urologists and vascular surgeons), may explain the increased medicalization of treating erectile disorder (Tiefer, 1994) and the relative neglect of psychological and interpersonal approaches (Rosen \& Leiblum, 1995). In addition, several investigators (e.g., Everaerd \& Dekker, 1985) have pointed to the

reluctance of many men and their partners to consider the emotional or interpersonal antecedents of the problem. [Whereas] . . . surgical or medical treatments may represent a "quick fix" for the disorder, they avoid the time-consuming and uncertain outcome of psychological treatment approaches. (Rosen \& Leiblum, 1995, p. 881 ).

Further studies need to establish whether recent developments in the understanding of relevant psychosocial and interpersonal factors (Rosen \& Leiblum, 1995) may result in efficacious psychosocial treatments for male sexual dysfunctions.

\section{Alcohol Abuse and Dependence}

Alcohol abuse and dependence' are prevalent, costly, and debilitating problems not only for drinkers but also for their spouses and family members (Edwards \& Steinglass, 1995). In addition to health care costs due to drinking-related diseases, problem drinking is associated with higher rates of psychological and physical problems among nondrinking spouses (e.g., Moos, Finney, \& Gamble, 1982) and with marital discord, separation, and aggression (Kantor \& Straus, 1990; Leonard \& Jacob, 1988; O'Farrell \& Murphy, 1995).

Clinical reports and research findings illustrating how problem drinking is intertwined with couple and family interaction have provided a rationale for developing couple-level interventions and investigating their efficacy (McCrady \& Epstein, 1995). For example, O'Farrell (1993) described marital conflict as both an antecedent and a consequence of problem drinking: Although drinking may lead to marital conflict, problematic marital interactions often appear to stimulate drinking or precipitate renewed drinking even by abstinent alcoholics. Indeed, research by Jacob and his colleagues (e.g., Jacob \& Leonard, 1988) suggests that, for some couples, drinking is associated with improved functioning and marital satisfaction (at least in the short run), whereas, for others, the effect of alcohol in the system is clearly negative. One way or the other, couple functioning may play an important role in maintaining or chang-

\footnotetext{
${ }^{1}$ The term alcoholism has often been used by adherents of the disease model, whereas problem drinking often reflects a psychosocial conceptualization of heavy drinking. We use these terms interchangeably, attempting to stay faithful to their use by the reviewed investigators and regardless of our own view on the disease versus psychosocial explanation of the phenomenon.
} 
ing the drinking. Observations such as these underscore the clinical relevance of addressing marital patterns that may precipitate or maintain problem drinking if one is to help an alcoholic achieve and maintain sobriety.

In comparison with couple treatments for the other disorders reviewed here, research on couple treatments for alcohol problems has typically entailed more diverse outcome criteria. There is growing consensus among researchers in this area that symptom reduction defined as "percent days abstinent" cannot suffice as the sole, or even the most important, outcome (Heather \& Tebbutt, 1989; O'Farrell et al., 1996; Zweben, 1986). For example, patients with antisocial personality disorder drink less frequently (Longabaugh, Beattie, Noel, Stout, \& Malloy, 1993), but they may do more harm while drinking. Similarly, for alcoholics who drink heavily but episodically (Jacob \& Leonard, 1988 ), the criterion of percent days abstinent can be misleading. Even when binge drinkers reduce the number of days on which they drink heavily, negative consequences such as job loss, arrest, hospitalization, and marital violence can be condensed into these fewer days. Thus, in the current review, efficacy status was established on the basis of quantity and frequency of consumption, as well as a combined index of drinking and negative consequences associated with drinking.

Our review of more than 30 studies as well as of recent review articles (e.g., Edwards \& Steinglass, 1995; Miller et al., 1995) revealed that even in a prolific area such as alcoholism research, the number of studies that directly tested treatment efficacy and had both design and outcomes consistent with Chambless and Hollon's (1998) inclusion criteria was small. We identified two such programmatic evaluations of the efficacy of couple-based interventions for drinking problems: (a) Azrin and colleagues' community reinforcement approach (CRA) for male alcoholics and their significant others and (b) O'Farrell and colleagues' adaptation of BMT for male alcoholics and their marital-cohabiting partners. Alcohol treatment studies are limited in their design options. Heavy drinkers' reluctance to change and the immediate dangers involved in excessive drinking rule out assigning them to no-treatment or waiting list control groups. Virtually all alcohol treatments are compared with another active intervention, at least at the treatment-as-usual level.

\section{Community Reinforcement Approach}

CRA (Azrin, 1976) is one of the broadest spectrum interventions evaluated in controlled studies. This behavioral treatment involves spouses, family members, and other individuals from drinkers' social networks in the treatment process and is designed so that the vocational, marital-familial, and social reinforcers of the drinker are removed when he or she drinks. Toward this end, significant others are trained initially in how to engage the drinker in the treatment program (Sisson \& Azrin, 1986) and then in how to provide and remove reinforcers during drinking episodes. Consistent with the operant approach, reinforcers are constructed from a functional analysis of drinking behavior. In addition, all participants receive training in drink refusal, relaxation, control of drinking urges, positive methods of dealing with social situations that often precede drinking, and advice on social and recreational activities. Additional training, including job-finding counseling, behavioral couples therapy empha- sizing reciprocity, and social skills training for socially isolated participants, is available for those who need it. The latter intervention encourages socially isolated drinkers to establish social relationships that can serve as a natural deterrent to drinking (Azrin, Sisson, Meyers, \& Godley, 1982). This treatment can be viewed mainly as a PFAI with some components of disorderspecific intervention. General (marital) intervention is provided only if broader marital problems arise.

Efficacy status. Azrin and colleagues have conducted four controlled studies evaluating the efficacy of CRA for treatment of male problem drinkers. One study aimed at achieving the engagement of the alcoholic in treatment (Sisson \& Azrin, 1986); two investigated the acute phase, targeting drinking behaviors (Azrin et al., 1982; Hunt \& Azrin, 1973); and one included both acute and relapse prevention interventions (Azrin, 1976). In all of these studies, CRA demonstrated superior outcomes to treatment as usual in terms of treatment engagement, drinking, and subsequent hospitalizations, as well as employment, social, and marital adjustment (see Table 5 for a summary of results). Whereas two of these studies are limited by poorly defined samples, all participants in the Azrin (1976) and Hunt and Azrin (1973) studies were admitted to an alcoholism treatment unit at a state hospital as "diagnosed alcoholic" (p. 92), with extensive records of alcoholism, and all reported physiological symptoms of withdrawal from alcohol on admittance. Thus, these two studies served as the main source for establishing the efficacy status of the treatment. The sample in Azrin et al.'s (1982) study has not been clearly defined. Participants in that investigation were included on the basis of their complaints about abuse of alcohol rather than on the basis of a formal diagnosis. Therefore, the study does not qualify in terms of providing evidence for efficacy. It does qualify, however, in terms of illuminating issues of effectiveness, and it is reviewed as such.

The efficacy status of CRA is evaluated here on the basis of two controlled studies: Azrin (1976) and Hunt and Azrin (1973). Whereas the former targeted the acute phase of treatment, the latter included both acute and relapse prevention interventions. In both studies, CRA demonstrated superior outcomes to treatment as usual in terms of treatment engagement, drinking and subsequent hospitalizations, and employment, social, and marital adjustment. Despite its small scale, Azrin's (1976) study yielded a significant group difference, with CRA $(n=10)$ participants recording $98 \%$ days abstinent versus $45 \%$ in the treatment-as-usual group (Azrin, 1976). The goal of this study was to increase the number of clients who maintain treatment gains and remain totally abstinent. To that end, Azrin used what is probably the first controlled evaluation of relapse prevention, setting up a buddy system in the community (a former client who had been abstinent for at least a year). In addition, the acute phase of the treatment was expanded to include partnerfamily-assisted disulfiram (Antabuse) contracts and a disulfiram assurance component that included the addition of specific training in adhering to disulfiram treatment. A significant other accompanied clients to all sessions; couples role-played situations in which the drinker wanted to stop taking the disulfiram, and the couples received disorder-specific communication training (Azrin, Naster, \& Jones, 1973) aimed at casting the significant other's role as a caring supportive person rather than as a watchdog. Couples were encouraged to call their counselors 
Table 5

Empirical Status of Couple Therapy for the Treatment of Alcohol Abuse and Dependence

\begin{tabular}{|c|c|c|c|}
\hline $\begin{array}{l}\text { Possibly efficacious } \\
\text { and specific treatment }\end{array}$ & Study & Treatment conditions & $\begin{array}{l}\text { Major } \\
\text { results }^{\mathrm{a}}\end{array}$ \\
\hline \multirow[t]{3}{*}{ CRA } & Sisson \& Azrin (1986) & $\begin{array}{l}\text { 1. CRA }(n=7) \\
\text { 2. Treatment as usual }(n=5)\end{array}$ & $1>2$ \\
\hline & Hunt \& Azrin (1973) & $\begin{array}{l}\text { 1. CRA }(n=8) \\
\text { 2. Treatment as usual }(n=8)\end{array}$ & $1>2$ \\
\hline & Azrin (1976) & $\begin{array}{l}\text { 1. CRA }(n=19) \\
\text { 2. Treatment as usual }(n=19)\end{array}$ & $1>2$ \\
\hline \multirow[t]{2}{*}{ BMT } & O'Farrell et al. (1985) & $\begin{array}{l}\text { 1. Group BMT }+ \text { commitment enhancement presessions }+ \\
\text { disulfiram contract }(n=10) \\
\text { 2. Group interactional couple therapy }(n=12) \\
\text { 3. Individual treatment as usual + relapse prevention }(n=12)\end{array}$ & $1>3>2$ \\
\hline & O'Farrell et al. (1993) & $\begin{array}{l}\text { 1. BMT + relapse prevention }(n=30) \\
\text { 2. Attention-placebo }(n=29)\end{array}$ & $1>2$ \\
\hline
\end{tabular}

Note. $\quad$ CRA $=$ community reinforcement approach; BMT $=$ behavioral marital therapy.

${ }^{a}$ Major results include statistically significant differences among treatment conditions at posttest; see text for follow-up results. Treatments are designated by number from previous column (e.g., $1>2$ indicates that Treatment 1 is statistically superior to Treatment 2 in percent days abstinent or a drinking-outcome index at posttest).

if they encountered difficulties in compliance. In addition to demonstrating clear advantages over the treatment-as-usual group, the improved CRA met its intended goal: After treatment, clients were drinking on only $2 \%$ of days. In addition to less drinking, the CRA group had higher rates of employment and lower rates of institutionalization and marital separation. Results from Hunt and Azrin (1973) were somewhat less dramatic but nevertheless impressive, with $86 \%$ and $29 \%$ abstinent days in the CRA and treatment-as-usual groups, respectively. On the basis of the superiority of CRA over treatment as usual, and given that this finding has not yet been replicated by an independent investigator, CRA meets criteria for a possibly efficacious and specific treatment.

Follow-up results. CRA clients maintained over $90 \%$ abstinent days through the 2-year follow-up in Azrin's (1976) study and $86 \%$ abstinent days through the 6-month follow-up in Hunt and Azrin's (1973) study.

Effectiveness. CRA is cost-effective, with both lower reported cost and required staff time per participant than treatment as usual. Moreover, attrition was less than $10 \%$, comparing favorably to average dropout rates of $50 \%-70 \%$ for outpatient alcoholism treatment reported in the literature (Noel, McCrady, Stout, \& Fisher-Nelson, 1987; Wierzbicki \& Pekarik, 1993). Also, alcoholics exposed to the CRA approach were more likely to start treatment. A small-scale study aimed at treatment engagement (Sisson \& Azrin, 1986) found CRA to be superior to usual recruitment efforts.

Despite its cost-effectiveness, the application of CRA requires intensive professional, familial, and community resources. Is this high level of involvement necessary, and do all persons need the same intervention? In an attempt to address this question, Azrin et al. (1982) used an additive, constructive randomized group design to compare (a) traditional disulfiram treatment ( $n=14$ ), in which clients, accompanied by a significant other to the first session, were prescribed a daily dose of disulfiram and received five sessions of alcohol education; (b) disul- firam assurance $(n=15)$, similar to the traditional group with the addition of partner-family-assisted disulfiram contracts (Azrin, 1976); and (c) the CRA package plus disulfiram assurance $(n=14)$. Because participants in this investigation were included on the basis of their complaint of abuse of alcohol rather than on the basis of a formal diagnosis, the results could not be used for efficacy judgments. However, the study points to an important issue of effectiveness. As in the other two studies mentioned earlier, the CRA group outperformed the other two by maintaining $97 \%$ abstinent days over a period of 6 months posttreatment (less than 1 day drinking per month). The other two groups (the traditional disulfiram treatment and disulfiram assurance groups) maintained significantly lower percent abstinent days ( $46 \%$ and $74 \%$, respectively). At 3 to 6 months posttreatment, compliance with disulfiram ingestion was close to zero in the traditional treatment condition. Azrin et al.'s post hoc analysis, however, revealed that the superiority of CRA over treatment as usual did not generalize to all clients: Single clients benefited more from CRA than from the other two treatments ( $94 \%$ vs. $23 \%$ and $27 \%$ abstinent days, respectively), whereas married couples reached the ceiling of $99 \%$ abstinent days in the partner-family-assisted disulfiram assurance and CRA groups (but not in the traditional disulfiram treatment, in which they averaged 58\% abstinent days). In other words, whereas CRA was efficacious for both single and married couples, the partner-family-assisted disulfiram assurance treatment was efficacious only for people who had a (marital-cohabiting) partner. Most important, the minimal, partner-family-assisted disulfiram assurance treatment was as effective for married couples as the more extensive and costly CRA, suggesting that the spouse's involvement in disulfiram contracts may suffice to facilitate other, more reinforcing activities that compete with drinking behavior. Azrin et al. (1982) suggested that "single clients should be given the combined [CRA] treatment; married clients require only the disulfiram assurance program"' (p. 111). This recommendation seems somewhat premature given that this 
post hoc Patient $\times$ Treatment interaction effect has not been replicated.

\section{Behavioral Marital Therapy}

O'Farrell and his colleagues developed a highly structured, multicomponent treatment program called Counseling for Alcoholic Marriages (Project CALM). In its present, revised form, this treatment includes (a) presessions with each couple, (b) group BMT, and (c) a relapse prevention module (O'Farrell, Choquette, Cutter, Brown, \& McCourt, 1993). In the 6 to 8 weekly presessions, therapists work with the couple to build commitment to the treatment and establish a formal partnerassisted disulfiram contract negotiated between the spouses. The subsequent BMT groups are conducted in 10 weekly 2-hr sessions.

The BMT is sequential and clearly manualized and includes midweek phone prompts from the group observer, who checks for progress (e.g., homework completion) and confirms attendance for the next meeting. Earlier sessions are designed to increase positive exchanges by helping spouses notice and increase positive behavior, leading to a focus on marital communication and problem-solving training in later sessions. Each session begins with a focus on compliance with partner-assisted disulfiram contracts and other homework assignments, as well as on drinking and urges to drink between sessions. The session proceeds with the introduction of new material, instruction in and rehearsal of targeted skills, discussion of homework assignments, and problem solving. Although there is a focus on drinking in each group session, problem solving is primarily focused on building relationship skills. The relapse prevention module consists of 15 conjoint couple (rather than group) sessions with increasing intersession spacing over a 12-month period. In addition to applying a relapse prevention plan (e.g., identifying highrisk situations or early warning signs and dealing with lapses; Marlatt \& Gordon, 1985), therapists help couples maintain marital and drinking gains achieved in the BMT group by urging them to continue the disulfiram contract and other couple-level and individual activities that worked well for them. The treatment can be viewed mainly as a general marital intervention with embedded partner-assisted modules.

Efficacy status. In their first study of Project CALM, O'Farrell, Cutter, and Floyd (1985) randomly assigned 34 alcoholic men to one of three treatment formats: (a) a BMT couples group, (b) an interactional couples group, and (c) individual treatment as usual. Both BMT and the interactional treatment were preceded by one orientation and commitment enhancement presession. Disulfiram contracts were included as part of the BMT (but not the interactional) group and were encouraged in the individual treatment-as-usual format. The interactional group shared the goals of decreasing drinking and conflict about drinking and increasing positive interaction between spouses but emphasized mutual support, relational insight, and sharing of feelings rather than behavioral rehearsal and skill training. Clients viewed BMT and the interactional treatments as equally credible and satisfactory. O'Farrell et al. (1985) used state-of-the-art outcome measures for drinking (time-line follow-back interview and breath tests) and included indexes of negative consequences of drinking as well as marital quality. Moreover, the investigators measured treatment credibility and integrity of treatment imple- mentation. On the basis of an index of drinking outcome, O'Farrell et al. (1985) found better posttreatment outcomes for alcoholics treated in the group BMT format. This index included percentage of days abstinent as well as negative consequences of drinking (i.e., costs incurred by patients for alcohol-related job loss, hospitalizations, and arrests during the 2 years after treatment; O'Farrell et al., 1996). Results regarding percent days abstinent per se were more equivocal: Both the BMT and the treatment-as-usual groups reached high averages (99\% and $91 \%$, respectively, not significantly different from each other), whereas the interactional group lagged somewhat behind the BMT group, with $83 \%$ days abstinent.

The second study of Project CALM (O'Farrell et al., 1993) was an experimental investigation of the efficacy of a BMTbased relapse prevention intervention. Couples who successfully completed a revised version of the extended BMT treatment (including six to eight commitment enhancement presessions) were randomly assigned to receive 12 months of relapse prevention intervention or measurement only. The findings from this study represented somewhat of a reversal of the O'Farrell et al. (1985) results. Whereas the differences between the treated and untreated clients on percent days abstinent were significant both 6 months and 12 months post-BMT, a comparison of adverse consequences of drinking did not yield significant differences between the treated and untreated clients. Taken together, the studies by O'Farrell and colleagues $(1985,1993)$ place the entire package of Project CALM in the possibly efficacious and specific category.

Follow-up results. In a cost-benefit analysis of the O'Farrell et al. (1993) data, O'Farrell et al. (1996) reported better results on the index of drinking outcome and the cost-benefit ratio 24 months after the treatment.

Clinical significance. When O'Farrell et al. (1985) used a clinical significance cutoff criterion of at least $95 \%$ abstinent days, all (100\%) BMT clients versus $58 \%$ of the interactional and treatment-as-usual control groups met the criterion. Given that, on average, clients in the treatment-as-usual group had $9 \%$ of days on which they were drinking, the clinical significance data suggest that a substantial number of treatment-as-usual clients who did not meet the cutoff criteria still drank at posttest, even if on very few days. These few days, however, translate to 2-3 drinking days per month (vs. less than half a day for the BMT clients), during which much harm can be done and high costs can be incurred. This interpretation of the data is further augmented by the finding of higher levels of negative consequences of drinking in the treatment-as-usual group. Recent findings of O'Farrell and Murphy (1995) underscore the meaning of these clinical significance data: In comparison with relapsed alcoholics, clients who remitted after BMT were much less likely to be involved in marital violence.

Effectiveness. Project CALM is well documented and easy to disseminate, and it can be implemented in a group format with reportedly high levels of treatment acceptance and satisfaction by participants. A critical element in the cost-effectiveness of this treatment is the reduction in negative consequences of drinking and the unusually low client attrition rates reported in the efficacy studies: $3 \%$ and $12 \%$ in the 1985 and 1993 studies by $O$ 'Farrell et al., respectively. These figures compare favorably with the average dropout rates of $50 \%-70 \%$ for outpatient alcohol treatment reported in the literature (Noel et al., 1987; Wierz- 
bicki \& Pekarik, 1993). On the other hand, the evidence to date does not allow for generalization of the efficacy status or effectiveness indicators of Project CALM to BMT that does not include the other components of the treatment (i.e., motivational presessions and the use of disulfiram). However, it is quite unlikely that disulfiram was largely responsible for the efficacy status of the treatment. The prescription of disulfiram alone has yielded equivocal results in the treatment of alcoholism in other investigations (e.g., Azrin et al., 1982; Fuller et al., 1986), and there is little evidence to support the efficacy of detoxification programs that are not followed by an outpatient intervention. A small-scale study $(n=16)$ of couple-group BMT without disulfiram (Bowers \& Al-Redha, 1990) found BMT to be significantly better than individual treatment as usual in maintaining drinking reduction at 6-month follow-up, thus augmenting confidence that the psychosocial treatment rather than disulfiram is responsible for the results obtained by O'Farrell and his colleagues. (Because the superiority of BMT over treatment as usual in Bowers and Al-Redha's [1990] study was not obtained at posttest, this study did not meet criteria for inclusion in the review of efficacy status.)

Generalization may be further limited by the fact that about half of the participants in O'Farrell et al.'s (1985) study were recruited to the study after an inpatient alcohol treatment for detoxification or rehabilitation, or both. Finally, O'Farrell et al.'s (1985) post hoc analysis replicated a limitation to effectiveness noted by other BMT researchers (e.g., Jacobson et al., 1986; Zimmer, 1987); that is, more distressed couples benefited less from the treatment.

Should all clients who successfully complete BMT receive a relapse prevention intervention? O'Farrell et al. (1993) found that, for clients engaging in more severe drinking, the BMTbased relapse prevention intervention was more effective than the no-treatment control throughout the 12-month follow-up period. For less severe clients, however, the advantage of the relapse prevention intervention was evident at 6 but not 12 months posttreatment. Thus, the effect of the relapse prevention intervention seems to have been less generalizable to less severe drinkers and most pertinent for the clients who needed it most, the more severe drinkers.

The package of Project CALM requires a high level of spouse involvement in the treatment. Does increased involvement of the spouse result in higher effectiveness? In an attempt to answer this question, McCrady et al. (1986) compared three alcoholism treatments that varied in amount of spousal involvement: (a) a partner-assisted, minimal spouse involvement intervention in which the wife observed her husband's treatment and provided a supportive presence, (b) a disorder-specific intervention (alcohol-focused spouse involvement) in which the spouse was taught specific skills in dealing with drinking and drinkingrelated behavior, and (c) alcohol BMT in which general marital therapy was added to the disorder-specific components, focusing on both drinking and marital communication. Results indicated that, although all clients improved, the groups did not differ from each other on either abstinence or negative consequences outcome indexes (McCrady, Stout, Noel, Abrams, \& Nelson, 1991). Whereas the study does not allow for efficacy conclusions, it suggests two implications for effectiveness: (a) A minimal spouse-involved intervention may be as effective as conjoint BMT, and (b) BMT appears to yield durable improvement rates when implemented in a conjoint couple (rather than group) format.

\section{Conclusions}

Considering the various findings to date, involvement of significant others, especially cohabiting partners (e.g., spouses), in the various phases of alcoholism treatment has enhanced treatment outcomes. Partner-assisted interventions have helped to engage alcoholics in initial treatment (e.g., Sisson \& Azrin, 1986; see Table 5). Two rather comprehensive treatment packages-Azrin's (1976) CRA and O'Farrell et al.'s (1985, 1993) Project CALM - have shown efficacy in terms of drinking reduction and harm reduction, as well as in preventing relapse. Both of these interventions should be considered possibly efficacious (and specific) at this point, pending independent replications.

Evidence of effectiveness is sparse and equivocal, yet highly encouraging. Both projects provided findings regarding two important and possibly related questions: (a) How comprehensive should the intervention be to retain its efficacy status? and (b) For whom would these treatments be most effective? Although current trends appear to involve more comprehensive interventions for problem drinkers, the indicators of effectiveness suggest that more minimal interventions might be of benefit for some problem drinkers. More specifically, both McCrady et al.'s ( 1986) minimal spouse involvement and Azrin's disulfiram assurance intervention yielded promising, if tentative, results. We should also note that the unique contribution of partnerassisted disulfiram contracts embedded within the package of Project CALM (O'Farrell et al., 1993) has not been examined.

Finally, both projects included findings relevant to the elusive question of treatment matching (i.e., the possibility that couple or family treatments may be differentially effective depending on characteristics of either the drinker or the social-familial relationships in which drinking occurs). Although researchers of alcoholism treatments have recognized that not all alcoholics are alike and that not all benefit from the same treatments, Patient $\times$ Treatment statistical interactions necessary to justify empirically guided matching of clients to treatments have been notoriously difficult to establish and replicate (Miller, 1992; Shoham \& Rohrbaugh, 1995). In fact, the recent well-publicized results of Project MATCH (Project MATCH Research Group, 1997) suggest that the promise of matching treatments to subtypes or characteristics of alcoholics remains largely unfulfilled. Like most Aptitude $\times$ Treatment interaction research on psychosocial treatments ( Shoham-Salomon \& Hannah, 1991; Snow, 1991 ), however, Project Match focused exclusively on characteristics of individual alcoholics in evaluating hypothesized matching dimensions for individually focused treatments. Whether matching prospects will be equally elusive for couple and family treatments is an open question. Our review of research on the CRA and Project Calm packages noted several potentially relevant findings related to the role of (a) marital status in predicting differential responses to components of CRA (Azrin et al., 1982), (b) marital adjustment as a predictor of responses to BMT (O'Farrell et al., 1985), and (c) problem severity as a moderator of BMT-based relapse prevention (O'Farrell et al., 1993). When the unit of treatment is more than one person (e.g., a couple or family), it may be naive to 
expect characteristics of only one person (the drinker) to have a strong moderating effect on responses to different treatments.

\section{Schizophrenia}

The confluence of the deinstitutionalization movement, research linking stress in the family to higher relapse rates, and increased understanding of the burden of mental illness on relatives led to the development of several family intervention programs for schizophrenia over a relatively brief period. Implicit in all of these family treatment programs is their acceptance of the stress vulnerability-family coping skills model for improving the prognosis of schizophrenia (Mueser \& Glynn, 1995). This model represents an adaptation of traditional stress vulnerability models for schizophrenia (e.g., Nuechterlein \& Dawson, 1984 ) to incorporate the family as a possible source of stress or as protection against stress.

According to this model, functional capacity and course of illness are determined by the interplay between biological vulnerability and stress. Vulnerability can be decreased by antipsychotic medications and worsened by substance abuse. Stress on the patient, such as exposure to highly critical or intrusive behavioral styles of relatives (conceptualized as expressed emotion; Leff \& Vaughn, 1985), can impinge on vulnerability, leading to relapses. However, coping efforts can buffer against the negative effects of stress. Similarly, living with a patient with schizophrenia can be stressful for relatives, whereas effective coping strategies can lessen the noxious effects of stress on all family members. Thus, newer family intervention programs share the general goals of promoting adherence to antipsychotic medications, reducing stress in the family, and enhancing the coping skills of all members.

Recently developed models of family intervention vary considerably in terms of duration of treatment. Many short-term educational or psychotherapeutic programs have been developed for families; these programs have demonstrated beneficial effects for relatives, including decreases in family burden and distress and improved self-efficacy (Abramowitz \& Coursey, 1989; Birchwood, Smith, \& Cochrane, 1992; Glynn, Pugh, \& Rose, 1993; Mills \& Hansen, 1991; Sidley, Smith, \& Howells, 1991; Smith \& Birchwood, 1987; Solomon, Draine, Mannion, \& Meisel, 1996a). However, lack of evidence supporting the efficacy of these programs for improving relapse and rehospitalization rates of patients with schizophrenia has tempered enthusiasm for short-term approaches (e.g., Glick et al., 1985; Solomon, Draine, Mannion, \& Meisel, 1996b; Vaughn et al., 1992), although at least one study (Goldstein, Rodnick, Evans, May, \& Steinberg, 1978) has reported beneficial effects of a 6-week family intervention program for patients who had experienced either a first or second schizophrenic episode. Because shortterm family programs tend not to have positive effects on longterm patient outcomes and, thus, would not be viewed as efficacious by the current standards, we confined our review to longterm family treatment lasting 6 months or more.

Despite differences among the long-term family treatments in terms of characteristics such as format (e.g., multiple vs. single family) and setting (e.g., home based vs. clinic based), these interventions share many common features, as noted by Lam (1991), Glynn (1993), and Mueser (1996). All family treatment programs reviewed here provide education about schizophrenia (e.g., symptoms, biological theories, early warning signs of relapse, medication, and principles of treatment) and avoid blaming family members or pathologizing their coping efforts. Effort is expended toward helping family members improve their communication and problem-solving skills, either through social skills training or discussion. Family programs are focused on fostering the development of all family members, not just the patient, including encouraging members to expand their social supports outside the family network. Finally, all of these programs take a long-term perspective to improving the ability of the family to manage the illness and endeavor to instill hope that change is possible.

Earlier in this article, three approaches to couples or family interventions for adult disorders were distinguished: partnerassisted (or family-assisted) interventions, disorder-specific interventions, and general couples or family therapy. Family treatment programs for schizophrenia incorporate elements of all three types of approaches. As an example of family-assisted intervention, through the use of family education and role-playing, patients might learn how to identify problematic medication side effects and to discuss them with their physician, thereby reducing the possibility of medication noncompliance. An example of a disorder-specific family intervention would be training family members in communication skills to reduce the patient social withdrawal that functions as an escape from highly critical or intrusive interactions with relatives. Teaching family members problem-solving strategies for resolving conflicts and achieving mutually desirable goals is an example of general family therapy applied to schizophrenia.

Because of their general similarities and the fact that most of them consist of multiple components that reflect all of the preceding approaches to family involvement, current long-term family treatments for schizophrenia were reviewed collectively. However, as noted in the following section, these interventions can be broadly distinguished in terms of their predominant theoretical orientation (behavioral, supportive, or family systems). As such, the classification of EST status was determined for all of the interventions as a whole, as well as separately for each theoretical approach.

\section{Efficacy Status}

The common dependent variable in studies evaluating the efficacy of family interventions for schizophrenia is the cumulative rate of relapse of psychotic symptoms over the treatment period. Most studies have included patients who have recently experienced a relapse and are therefore at increased risk of a subsequent relapse; thus, examination of relapse rates provides a valuable index of the overall effects of the family intervention on the course of the illness. Although psychotic relapses do not invariably result in rehospitalization, they often do, and treatment of such relapses is the primary reason for psychiatric hospitalization. Some studies have not formally evaluated patient psychopathology over time but, instead, have examined the effects of family treatment on rehospitalization rates. Therefore, our evaluation of the efficacy status of family interventions for schizophrenia is based on changes in relapse or rehospitalization rates.

Table 6 summarizes controlled studies comparing a family intervention program with routine (no family) treatment or com- 
BAUCOM, SHOHAM, MUESER, DAIUTO, AND STICKLE




paring two different family treatments and reporting outcomes for at least 18 months after the initiation of treatment. In all of these studies, patients were in regular contact with their families and were living in the community. In addition, most studies included patients who had recently experienced a psychotic relapse and rehospitalization. In all studies, patients received routine treatment for schizophrenia, including antipsychotic medication, case management, and access to other rehabilitation programs.

Behavioral family therapy. Four of the studies presented in Table 6 evaluated family intervention programs with a strong behavioral orientation. In general, the behavioral models are distinguished by their incorporation of traditional elements of cognitive-behavioral therapy such as functional assessment, teaching skills, homework, and time-limited treatment. Typical of these models is that of Falloon, Boyd, and McGill (1984; see also Mueser \& Glynn, 1995), which combines education with training in communication and problem-solving skills in a program designed to better manage the illness without the assistance of professionals. Another variant is that of Barrowclough and Tarrier (1992), which provides education combined with training in stress management, relapse prevention, and goal attainment.

Among the four studies that compared behavioral family intervention programs with routine treatment, three demonstrated significant reductions in relapse rates (Falloon et al., 1984; Randolph et al., 1995; Tarrier et al., 1989). The fourth study (Xiong et al., 1994) did not find significant differences in relapse rates, although patients who received family treatment were hospitalized less over the 18-month follow-up period than patients who received routine treatment. An additional study by Linszen et al. (1996), not included in Table 6, compared the effects of standard treatment plus behavioral family therapy (Falloon et al., 1984) with those of standard treatment plus intensive individual therapy. Nine-month cumulative relapse rates were quite low for both groups (16\% and $15 \%$, respectively), indicating the equivalence of behavioral family treatment to individual treatment. In interpreting this finding, however, it should be noted that the sample consisted of recent-onset schizophrenics rather than relapsed patients; thus, the unusually low relapse rates may be a function of sample characteristics rather than the treatments. Taken together, the findings of these studies indicate that behavioral family interventions should be considered efficacious and specific for improving long-term outcomes of schizophrenia.

Supportive family therapy. In Kuipers, Leff, and Lam's (1992) model, families participate in individual and group educational sessions about schizophrenia and its management. McFarlane (1990) developed a program in which families provide support for each other and discuss solutions for common problems in multiple-family group meetings. Although this approach incorporates problem solving, its main purpose is to provide a vehicle for families to share solutions to common problems and generate social support, with less emphasis on teaching a formal problem-solving strategy.

Five studies have evaluated the effects of supportive family interventions. The two studies that compared family treatment and routine care both found significantly lower relapse or rehospitalization rates associated with family treatment (Leff et al., 1985; Zhang, Wang, Li, \& Phillips, 1994). Three studies com- pared multiple-family groups and single-family interventions (Leff, Kuipers, Berkowitz, \& Sturgeon, 1985; McFarlane, Link, Dushay, Marchal, \& Crilly, 1995; McFarlane, Lukens, et al., 1995). The two studies by McFarlane et al. reported lower relapse rates for the multiple-family group format than for single-family therapy (based on Anderson, Reiss, \& Hogarty's, 1986, model), whereas Leff et al. (1990) reported no differences between the two formats. Similar to the studies involving a behaviorally oriented family intervention, these findings indicate that supportive family interventions are efficacious and specific for improving long-term outcomes of schizophrenia.

In the only study to date that has compared different family approaches, Zastowny, Lehman, Cole, and Kane (1992) reported no differences in outcome between two equally intensive family interventions: (a) a supportive family model based on principles outlined by Hatfield (1990) and (b) behavioral family therapy (Falloon et al., 1984). The sample included treatment-resistant patients with schizophrenia who were being prepared for discharge into the community. Families received 16 weekly sessions while the patient was in the hospital, followed by monthly sessions for an additional 12 months for 24 of 30 patients who were discharged. Rehospitalization rates over 12 months for the supportive and behavioral family treatments did not differ ( $33 \%$ and $45 \%$, respectively). Although this study is unique in its focus on more severely ill patients, the findings are consistent with those reviewed in Table 6, suggesting that there are no differences in efficacy between the behavioral and supportive family treatment models.

Family systems therapy. Anderson et al.'s (1986) family systems approach involves combining psychoeducation about schizophrenia with techniques from family systems therapy (e.g., reinforcing generational boundaries). Similar to the behavioral and supportive interventions, positive effects of this treatment have been reported in terms of reduced relapse rates relative to routine treatment (Hogarty et al., 1991). Given that only one study has explored the family systems approach, however, it is designated as possibly efficacious and specific.

Conclusions. In summary, the evidence to date supports the efficacy of several family treatment approaches for improving relapse and rehospitalization rates for patients with schizophrenia. As previously noted, the positive effects of family intervention across different theoretical orientations are probably a reflection of the many common components of treatment shared across the models, including a long-term commitment to treatment, provision of psychoeducation, attempts to reduce the stress levels in the family, and increased monitoring of the psychiatric illness. It is also of interest to note that different formats of family intervention (i.e., single-family treatment vs. multiplefamily groups ) result in similar reductions in relapse rates. In addition, the only study that compared the combination of single-family therapy and multiple-family groups with multiplefamily groups alone reported almost identical rehospitalization rates (Schooler et al., 1997), suggesting no incremental advantage to combining formats over providing only one treatment format. Taken together, the results suggest that manualized family interventions that use behavioral, supportive, or family systems models and provide treatment for at least 9 months are efficacious in reducing relapse rates in schizophrenia. There is an absence of data suggesting that any one model of family intervention is consistently superior to another (however, see 
McFarlane, Link, et al., 1995; McFarlane, Lukens, et al., 1995), and those family interventions designated as efficacious and specific demonstrate only that they are more beneficial than treatment as usual.

Given the preceding findings, it might be inferred that the theoretical orientation on which family interventions are based is irrelevant in predicting outcomes. However, there is evidence that at least one family approach may not be beneficial for treating schizophrenics. Köttgen, Sönnichsen, Mollenhauer, and Jurth (1984) employed an approach that involved the use of insight-oriented techniques and focusing on the past (e.g., exploring the origins of patients' and relatives' critical and hostile overinvolvement with each other). In contrast to the studies reviewed in Table 6, the authors failed to find beneficial effects on relapse rates of a family intervention program over 1 year. McFarlane, Link, et al. (1995) also reported negative outcomes with a group psychodynamic family approach that led them to discontinue randomization to this group before completion of their study. These results, in line with the negative findings of research on individual psychodynamic treatment for schizophrenia (Mueser \& Berenbaum, 1990), suggest that insight-oriented approaches are not useful with families of schizophrenic individuals.

\section{Follow-Up Results}

Among the studies reviewed in Table 6 , almost all provided family interventions for a period of 18-24 months; few relapse rate data were reported for follow-up periods beyond the termination of treatment. McFarlane (1990) explicitly states that his multiple-family group intervention is intended to be time unlimited, because a major function of the treatment is to facilitate the development of an improved social support system. Although the maintenance of family therapy effects over time would strengthen the efficacy of family interventions, it is debatable whether such long-term effects are necessary to deem family programs beneficial. Bellack and Mueser (1993) have pointed out that pharmacological interventions have time-limited effects in patients with schizophrenia and that it may be unrealistic to expect psychosocial interventions to have lasting effects for all patients in this population.

In two of the studies reviewed in Table 6, Randolph et al. (1995) and Tarrier et al. (1989) provided 12 and 9 months of different variants of behavioral family therapy, respectively, and then conducted follow-up evaluations 2 years after treatment initiation. Both studies reported that the cumulative relapse rates of patients who received family intervention were significantly lower at the 2-year assessment point than those of control patients, suggesting that some beneficial effects of family treatment were maintained 12 to 15 months after the end of therapy. In fact, Tarrier, Barrowclough, Porceddu, \& Fitzpatrick (in press) have reported that patients who received their 9-month family program (Tarrier et al., 1989) continued to have significantly lower relapse rates than control patients 5 to 8 years after the initiation of treatment.

\section{Clinical Significance}

Schizophrenia is a lifelong illness. Most pharmacological and psychosocial interventions are aimed at minimizing the impair- ments characteristic of the disorder and improving its long-term course rather than curing it. Therefore, the clinical significance of family intervention must be judged by the extent to which it produces clinically meaningful changes rather than its success in curing schizophrenia. As summarized in Table 6, family intervention across multiple studies was associated with a reduction in cumulative relapse (or rehospitalization) rates of approximately 50\%. Considering that symptom relapses and rehospitalizations are among the most vexing problems experienced by patients with schizophrenia, and given the high cost of inpatient hospitalization, family treatment appears to be a clinically significant intervention and one of the most potent psychosocial interventions available for schizophrenia (Penn \& Mueser, 1996).

The implied cost savings due to the effects of family intervention on reducing relapses and rehospitalization were studied in two of the investigations summarized in Table 6 (Falloon et al., 1984; Tarrier et al., 1989). In both studies, family intervention was found to result in lower overall treatment costs, primarily through reduced use of inpatient care (Cardin, McGill, \& Falloon, 1986; Tarrier, Lowson, \& Barrowclough, 1991). Thus, long-term family treatment programs that emphasize psychoeducation, support, and stress reduction are associated with both clinically significant effects and lower overall costs for patients with schizophrenia.

Although the effects of family intervention on relapse rates are clearly established, less research has addressed its effects on other areas of functioning such as social adjustment, work, and quality of life. Several studies have suggested that family intervention is associated with improvement in social functioning (Barrowclough \& Tarrier, 1990; Falloon, McGill, Boyd, \& Pederson, 1987; Hogarty et al., 1991). However, many other studies have not reported effects on other outcomes, so the broader effects of family treatment remain unclear at this time.

\section{Effectiveness}

There are three dimensions of the efficacy-effectiveness distinction that deserve brief mention: (a) the heterogeneity of patients for whom these interventions are helpful, (b) the ability of practicing clinicians to learn and implement family intervention models, and (c) the impact of cultural factors on outcomes. Regarding heterogeneity of patients, most studies have included primarily male patients with schizophrenia or schizoaffective disorder who have recently experienced a relapse and who are living with or are in regular contact with family members (usually parents). Although most family treatment studies have included women and relatives other than parents, the preponderance of men living with parents in these studies makes it unclear whether family treatment is equally beneficial for women and in work with other family constellations. The effects of family intervention programs on patients who have not recently experienced a relapse also are unknown, although their lower vulnerability to relapses in the absence of family intervention suggests that more statistical power will be necessary to detect the benefits of family treatment for such patients. Family expressed emotion status does not appear to mediate the effectiveness of family treatment programs. Early treatment studies focused on families high in expressed emotion (Falloon et al., 1985; Hogarty et al., 1991; Leff et al., 1985; Tarrier et al., 1989), although later 
studies also reported positive effects for mixed samples of families low and high in expressed emotion (e.g., McFarlane, Link, et al., 1995; Randolph et al., 1995).

Studies of family intervention have ruled out relatively few patients because of comorbid conditions. However, most studies have excluded patients with severe substance abuse. Considering the high comorbidity of substance use disorders in schizophrenia (Mueser et al., 1990; Regier et al., 1990), with approximately $25 \%-35 \%$ of patients meeting criteria for a recent use disorder, there is a need to evaluate the generalizability of family intervention programs for these dually diagnosed patients.

Regarding the ability of clinicians to learn and implement family treatments, most controlled studies of family intervention have taken place at psychiatric hospitals affiliated with university medical schools and have involved clinicians specially hired and trained for clinical research. However, several studies from China have been conducted with nonresearch clinicians practicing in mental health clinics or hospitals that serve broad catchment areas and are not directly affiliated with universities (Xiong et al., 1994; Zhang et al., 1993, 1994). These studies have reported positive effects of family intervention, including reduced relapse or rehospitalization, along with improved occupational functioning, social functioning, and family burden. In addition, Brooker et al. (1994) conducted a quasi-experimental study to evaluate the effects of training community nurses in behavioral family therapy (based on Falloon et al.'s, 1984, model). In a within-subjects design, families were placed on a waiting list for 6 months, followed by 12 months of family intervention, or assigned to a delayed treatment group for whom family treatment was initiated 1 year later. Families were assigned to either the waiting list or the delayed treatment group according to the point at which the community nurse received training in behavioral family therapy (i.e., either early or late in the course of the study). Family intervention was associated with a range of positive outcomes, including reductions in positive and negative symptoms, improved social functioning, and improvements in relatives' distress and knowledge of medication. Taken together, these limited findings suggest that family intervention techniques can be implemented successfully by trained community clinicians from different disciplines.

Finally, the role of cultural factors as a moderator of outcome has received only limited empirical attention. Telles et al. (1995) compared the effects of behavioral family therapy (Falloon et al., 1984) with standard treatment for 42 Latino patients with schizophrenia. In contrast to the studies reviewed in Table 6, there were no differences in relapse rates between the family intervention and standard treatment groups at 12 months (50\% and $41 \%$, respectively; $J$. Mintz, personal communication, November 1996). In fact, post hoc analyses indicated that poorly acculturated patients (i.e., patients with poor English-speaking skills and little involvement with Anglo culture outside of Latino culture) fared worse in the family intervention program than when they received only standard treatment, whereas, for wellacculturated patients, the program had no effect. These negative findings suggest that the efficacy of family intervention programs may interact with cultural factors. At a minimum, the findings indicate that family treatment models may need to be adapted for different cultures, as described by Xiong et al. (1994) in their modification of Falloon et al.'s (1984) model for the Chinese population. The positive effects of family inter- vention in controlled studies from China (Xiong et al., 1994; Zhang et al., 1994) suggest that the benefits from this treatment are not limited to Western cultures.

\section{Conclusions}

Although there is a wealth of evidence indicating that family programs are efficacious for schizophrenia, and some evidence supporting their effectiveness, family programs are still not available for most patients and their families (Dixon et al., 1997). It is unclear whether there are special barriers to family work for patients with schizophrenia (e.g., outdated theories that families cause schizophrenia; Mueser \& Glynn, 1995) or whether the slowness at implementing novel interventions is typical of the mental health field. It also is possible that the multitude of different family treatment models and manuals available has prevented any one model from achieving prominence and becoming the standard in the field. This may have resulted in less implementation of family intervention than if a single model had been developed and studied more intensively. More work is needed to understand how to implement family intervention programs for the broad range of clinicians working in the field.

\section{Concluding Remarks and Future Directions}

The present review sought to identify efficacious couplefamily-based interventions using criteria put forth by Chambless and Hollon (1998). In addition to reviewing the marital therapy literature, we also identified couple- and family-based treatments for a number of individual adult mental disorders. The results indicate that a number of couple- and family-based treatments appear to be beneficial for marital distress and individual disorders. At the same time, there are limitations to the generalizability of the findings of many of the studies reviewed and, by extension, limitations to the efficacy status of the treatments. First, almost all of these investigations were conducted in the United States or within another Western culture. Thus, it is not clear at present whether these interventions can be expected to offer the same benefits to patients regardless of cultural background. Second, studies typically included either all-male (e.g., alcoholism or schizophrenia) or all-female (e.g., depression, agoraphobia, or sexual disorders) samples. Thus, conclusions about the efficacy of the treatments reviewed are generalizable only to the gender on which the treatments have been tested to date. Even more pronounced, we were unable to locate few investigations that explored the efficacy of couple-family-based interventions for ethnic minorities within the United States. Given that many members of ethnic minority groups live in single-parent families and experience diverse stressors, the application of family-based interventions to minority populations is a pressing scientific and social need.

An additional potential limitation to the generalizability of our findings is that patients often were excluded from controlled trials if they met criteria for other co-occurring disorders. For example, evaluations of BMT typically have excluded couples with alcohol problems and sexual dysfunctions, and schizophrenia treatment studies typically have excluded patients with substance abuse disorders. The exclusion of such individuals does not imply that the patients in these investigations were easy to 
treat; in fact, almost anyone involved in clinical research would probably argue to the contrary. However, it does indicate that there is limited information to direct clinicians encountering clients who have several diagnoses or who do not fit cleanly into any formal diagnostic category. In addition, the selection of patients with comorbid conditions for controlled trials might enhance understanding of important moderator effects (e.g., couples therapy for depressed and maritally distressed patients).

Despite these limitations, a few concluding remarks are warranted regarding the treatments. The first part of this article reviewed couple-based treatments for relationship distress. By far the most widely evaluated approach to couples therapy is BMT, and findings to date indicate that it is an efficacious intervention for treating relationship distress. Other approaches (e.g., emotion focused, insight oriented, and cognitive) to marital therapy also appear to benefit distressed couples, although much less research has been conducted to evaluate them thus far. In short, the theory and practice of marital therapy appear to have much to offer to individuals who seek treatment for relationship problems. It is hoped that the possibly efficacious interventions reviewed here will continue to be the subject of empirical scrutiny and that future research will be directed at the question of how to match a distressed couple to the specific approach that will maximize the benefits of treatment.

The second portion of this review identified empirically supported couple- and family-based interventions for the treatment of individual adult disorders. One of the main findings of this endeavor was that spouses and families have been used in a multitude of ways to assist in the treatment of symptomatic individuals. To provide conceptual clarity regarding the nature of these various interventions, we attempted to delineate three types of couple- and family-based treatment approaches: (a) General marital and family therapy refers to the application of traditional approaches to address broad relationship issues thought to be etiologically associated with the disorder or implicated in the maintenance of symptoms; (b) disorder-specific couple-family interventions are those that focus on specific ways in which partners and family members interact or handle situations related to the individual's disorder that might contribute to the maintenance of the disorder or impede treatment gains; and (c) partner-family-assisted treatments are those that involve the partner or family member as a surrogate therapist or coach, with no attention to relationship issues. It was anticipated that organizing the various interventions in this manner would help to identify trends in the literature and synthesize general findings across the different disorders.

The present review revealed that the least commonly used of these formats in treating adult individual disorders was general marital-family therapy. In fact, this intervention was used as the sole treatment for only one disorder, depression, although it was used as part of a multi-component package of interventions for a number of disorders (see later discussion). Both of the marital approaches to treating depression (BMT and IPT) were based on clear formulations of how relationship distress is associated with depressive symptoms. Findings from the BMT studies indicate that marital therapy is likely to be most beneficial for depressed individuals who are experiencing co-occurring marital discord. Although it is not possible to generalize these findings across disorders, they suggest that general marital therapy may be most appropriate for treating individual psychopa- thology when there is co-occurring relationship distress that can be linked in some way to the nature of the presenting symptoms. Perhaps these general interventions have not been more frequently used because clear conceptualizations of the association between relationship functioning and individual symptoms have not yet been articulated. Alternately, it may be that such interventions have not been indicated because, in many cases, there is no apparent marital distress. In any case, the efficacy of general marital therapy for most individual disorders remains largely an empirical question.

In contrast, general marital and family interventions have more frequently been evaluated as part of a multicomponent package of interventions for a number of disorders (e.g., alcohol, schizophrenia, and sexual dysfunctions). Applied in this manner, these interventions appear to benefit diagnosed individuals. The use of general marital and family interventions in this manner is more likely to be acceptable to clients, who might object to receiving only marital therapy for treatment of a specific individual disorder.

A large number of the couple- and family-based interventions reviewed here were either partner-family-assisted or disorderspecific couple-family interventions. Whereas the former do not address relationship issues, the latter typically involve partners or family members in treatment with the goals of (a) educating them about the nature of the individual's disorder, (b) identifying and modifying the specific ways in which the patient's interpersonal environment is inadvertently enhancing or maintaining symptoms, and (c) fostering a relational context that encourages the patient to behave in ways that will lessen the disorder and help him or her to cope more effectively. Although we conceptually distinguished between these types of treatment, in practice they often were implemented together. At this stage in the evolution of these interventions, this seems appropriate. However, it is suggested that future investigators carefully consider the clinical rationale for using one or the other approach and develop an intervention strategy accordingly.

It is important to note that the partner-family-assisted and disorder-specific couple-family interventions do not assume that there are overt relationship difficulties that require attention. Rather, the wide variety of ways in which partners and families have been successfully used in treatment programs indicates that these interventions are appropriate even when there is no reported relational distress. Indeed, more important than the presence of overt relationship problems is likely to be a clear formulation of how specific marital and family interaction patterns are associated with the disorder in question.

It is our belief that couple- and family-based interventions have much to offer in the treatment of both interpersonal and individual difficulties. As the theoretical bases of marital therapy become richer and more complex and empirical evaluations of different approaches become more rigorous, we anticipate that a more sophisticated understanding of the role of significant relationships in individual functioning will evolve. It is our hope that this will lead to a more clearly explicated set of guidelines for involving spouses and other family members in treatment. As these couple- and family-based interventions become more refined, it will be necessary to determine their relative efficacy (e.g., general marital therapy vs. disorder-specific couples treatment vs. partner-assisted interventions ) as a means of establishing the extent to which relationship issues should be directly 
targeted so as to maximize treatment gains. The promising treatments identified here give reason to expect that much progress will be made in this regard.

\section{References}

Abramowitz, I. A., \& Coursey, R. D. (1989). Impact of an educational support group on family participants who take care of their schizophrenic relatives. Journal of Consulting and Clinical Psychology, 57, 232-236.

Alexander, J. F., Holtzworth-Munroe, A., \& Jameson, P. (1994). The process and outcome of marital and family therapy: Research review and evaluation. In A. E. Bergin \& S. L. Garfield (Eds.), Handbook of psychotherapy and behavior change (pp. 595-630). New York: Wiley.

American Psychiatric Association. (1980). Diagnostic and statistical manual of mental disorders (3rd ed.). Washington, DC: Author.

American Psychiatric Association. (1987). Diagnostic and statistical manual of mental disorders (3rd ed., rev.). Washington, DC: Author.

American Psychiatric Association. (1994). Diagnostic and statistical manual of mental disorders (4th ed.). Washington, DC: Author.

Anderson, C. M., Reiss, D. J., \& Hogarty, G. E. (1986). Schizophrenia and the Family. New York: Guilford Press.

Ansari, J. M. A. (1976). Impotence: Prognosis (a controlled study). British Journal of Psychiatry, 128, 194-198.

Arnow, B. A., Taylor, C. B., Agras, W. S., \& Telch, M. J. (1985). Enhancing agoraphobia treatment outcome by changing couple communication patterns. Behavior Therapy, 16, 452-467.

Azrin, N. H. (1976). Improvements in the community-reinforcement approach to alcoholism. Behaviour Reseanch and Therapy, 14, 339348.

Azrin, N. H., Besalel, V. A., Betchel, R., Michalicek, A., Mancera, M. Carroll, D., Shuford, D., \& Cox, J. ( 1980). Comparison of reciprocity and discussion-type counseling for marital problems. American Journal of Family Therapy, 8, 21-28.

Azrin, N. H., Naster, B. J., \& Jones, R. (1973). Reciprocity counseling: A rapid learning-based procedure for marital counseling. Behaviour Research and Therapy, $11,365-382$.

Azrin, N. H., Sisson, R. W., Meyers, R., \& Godley, M. (1982). Alcoholism treatment by disulfiram and community reinforcement therapy. Journal of Behavior Therapy and Experimental Psychiatry, 13, 105112.

Barlow, D. H., O'Brien, G. T., \& Last, C. G. (1984). Couples treatment of agoraphobia. Behavior Therapy, 15, 41-58.

Barlow, D. H., \& Waddell, M. T. (1985). Agoraphobia. In D. H. Barlow (Ed.), Clinical handbook of psychological disorders (pp. 1-68). New York: Guilford Press.

Barrowclough, C., \& Tarrer, N. (1990). Social functioning in schizophrenic patients. I. The effects of expressed emotion and family intervention. Social Psychiatry and Psychiatric Epidemiology, 25, 125129.

Barrowclough, C., \& Tarrier, N. (1992). Families of Schizophrenic Patients: Cognitive Behavioral Intervention. London, England: Chapman \& Hall.

Baucom, D. H. (1982). A comparison of behavioral contracting and problem-solving/communications training in behavioral marital therapy. Behavior Therapy, 13, 162-174.

Baucom, D. H., Burnett, C. K., Rankin, L., \& Sher, T. G. (1990, November). Cognitive/behavioral marital therapy outcome research: What is success? Paper presented at the 24th Annual Convention of the Association for the Advancement of Behavior Therapy, San Francisco, CA.

Baucom, D. H., Burnett, C. K., VanWidenfelt, B., Schilling, E., Sandin, E., \& Ragland, L. (in press). The prevention of marital discord and divorce: An international perspective. In K. Hahlweg, D. H. Baucom,
R. Bastine, \& H. J. Markman (Eds.), Prediktion und prevention von beziehungsstvungen und scheidung [Prediction and prevention of marital distress and divorce]. Bonn, Germany: BMFS.

Baucom, D. H., \& Epstein, N. (1990). Cognitive behavioral marital therapy. New York: Brunner/Mazel.

Baucom, D. H., Epstein, N., Sayers, S., \& Sher, T. G. (1989). The role of cognitions in marital relationships: Definitional, methodological, and conceptual issues. Journal of Consulting and Clinical Psychology, 57, 31-38.

Baucom, D. H., \& Hoffman, J. A. (1986). The effectiveness of marital therapy: Current status and application to the clinical setting. In N. S. Jacobson \& A. Gurman (Eds.), Clinical handbook of marital therapy (pp. 597-620). New York: Guilford Press.

Baucom, D. H., \& Lester, G. W. (1986). The usefulness of cognitive restructuring as an adjunct to behavioral marital therapy. Behavior Therapy, 17, 385-403.

Baucom, D. H., Sayers, S. L., \& Sher, T. G. (1990). Supplementing behavioral marital therapy with cognitive restructuring and emotional expressiveness training: An outcome investigation. Journal of Consulting and Clinical Psychology, 58, 636-645.

Beach, S. R. H., \& O'Leary, K. D. (1992). Treating depression in the context of marital discord: Outcome and predictors of response for marital therapy vs. cognitive therapy. Behavior Therapy, 23, 507-528.

Beach, S. R. H., Smith, D. A., \& Fincham, F. D. (1994). Marital interventions for depression: Empirical foundation and future prospects. Applied and Preventive Psychology, 3, 233-250.

Beck, J. G. (1995). Hypoactive sexual desire disorder: An overview. Journal of Consulting and Clinical Psychology, 63, 919-927.

Bellack, A. S., \& Mueser, K. T. (1993). Psychosocial treatment for schizophrenia. Schizophrenia Bulletin, 19, 317-336.

Bennun, I. (1985). Behavioral marital therapy: An outcome evaluation of conjoint, group and one spouse treatment. Scandinavian Journal of Behaviour Therapy, 14, 157-168.

Birchwood, M., Smith, J., \& Cochrane R. (1992). Specific and nonspecific effects of educational intervention for families living with schizophrenia. British Journal of Psychiatry, 160, 806-814.

Boelens, W., Emmelkamp, P., MacGillavry, D., \& Markvoort, M. (1980). A clinical evaluation of marital treatment: Reciprocity counseling vs. system-theoretic counseling. Behavior Analysis and Modification, 4, 85-96.

Bowers, T. G., \& Al-Redha, M. R. (1990). A comparison of outcome with group/marital and standard/individual therapies with alcoholics. Journal of Studies on Alcohal, 51, 301-309.

Bradbury, T. N., \& Fincham, F. D. (1990). Attributions in marriage: Review and critique. Psychological Bulletin, 107, 3-33.

Bray, J. H., \& Jouriles, E. N. (1995). Treatment of marital conftict and prevention of divorce. Joumal of Marital and Family Therapy, 21, 461-473.

Brooker, C., Falloon, I., Butterworth, A., Goldberg, D., Graham-Hole, V., \& Hillier, V. (1994). The outcome of training community psychiatric nurses to deliver psychosocial intervention. British Journal of Psychiatry, 165, 222-230.

Cardin, V. A., McGill, C. W., \& Falloon, I. R. H. (1986). An economic analysis: Costs, benefits and effectiveness. In I. R. H. Falloon (Ed.), Family management of schizophrenia (pp. 115-123). Baltimore: Johns Hopkins University Press.

Cerny, J. A., Barlow, D. A., Craske, M. G., \& Himadi, W. G. (1987). Couples treatment of agoraphobia: A two-year follow-up. Behavior Therapy, 18, 401-415.

Chambless, D. L., \& Hollon, S. D. (1998). Defining empirically supported therapies. Journal of Consulting and Clinical Psychology, 66, $7-18$.

Christensen, A., \& Jacobson, N. S. (1995, November). Acceptance in marriage. Paper presented at the meeting of the Association for Advancement of Behavior Therapy, New York, NY.

Christensen, L., \& Mendoza, J. L. (1986). A method of assessing change 
in a single subject: An alteration of the RC index. Behavior Therapy, 17, 305-308.

Cobb, J. P., Mathews, A. M., Childs-Clarke, A., \& Blowers, C. M. (1984). The spouse as co-therapist in the treatment of agoraphobia. British Journal of Psychiatry, 144, 282-287.

Craske, M. G., Burton, T., \& Barlow, D. H. (1989). Relationships among measures of communication, marital satisfaction, and exposure during couples treatment of agoraphobia. Behaviour Research and Therapy, 27, $131-140$.

Crowe, M. J. (1978). Conjoint marital therapy: A controlled outcome study. Psychological Medicine, 8, 623-636.

Crowe, M. J., Gillan, P., \& Golombok, S. (1981). Form and content in the conjoint treatment of sexual dysfunction: A controlled study. Behaviour Research and Therapy, 19, 47-54.

Dandeneau, M. L., \& Johnson, S. M. (1994). Facilitating intimacy: Interventions and effects. Journal of Marital and Family Therapy, 20, 17-33.

DeRubeis, R. J., \& Crits-Cristoph, P. (1998). Empirically supported individual and group psychological treatments for adult mental disorders. Journal of Consulting and Clinical Psychology, 66, 37-52.

Dewey, D., \& Hunsley, J. (1990). The effects of marital adjustment and spouse involvement on the behavioral treatment of agoraphobia: A meta-analytic review. Anxiety Research, 2, 69-83.

Dixon, L., Scott, J., Lyles, A., Fahey, M., Skinner, A., \& Shore, A. (1997). Adherence to schizophrenia PORT family treatment recommendations. Schizophrenia Research, 24, 221.

Dunn, R. L., \& Schwebel, A. I. (1995). Meta-analytic review of marital therapy outcome research. Journal of Family Psychology, 9, 58-68.

Edwards, M. E., \& Steinglass, P. (1995). Family therapy treatment outcomes for alcoholism. Journal of Marital and Family Therapy, 21, 475-509.

Eichel, E. W., Eichel, J. D., \& Kule, S. (1988). The technique of coital alignment and its relation to female orgasmic response and simultaneous orgasm. Journal of Sex and Marital Therapy, 14, 129-141.

Ellis, A. (1977). The nature of disturbed marital interactions. In A. Ellis \& R. Grieger (Eds.), Handbook of rational-emotive therapy (pp. 170-176). New York: Springer.

Emmelkamp, P. M. G. (1982). Phobic and obsessive-compulsive disorders: Theory, research, and practice. New York: Plenum.

Emmelkamp, P. M. G. (1994). Behavior therapy with adults. In A. E. Bergin \& S. L. Garfield (Eds.), Handbook of psychotherapy and behavior change (4th ed., pp. 379-427). New York: Wiley.

Emmelkamp, P. M. G., de Haan, E., \& Hoodguin, C. A. L. (1990). Marital adjustment and obsessive-compulsive disorder British Journal of Psychiatry, 156, 55-60.

Emmelkamp, P. M. G., \& de Lange, I. (1983). Spouse involvement in the treatment of obsessive-compulsive patients. Behavioural Research and Therapy, 21, 341-346.

Emmelkamp, P. M. G., \& Gerlsma, C. (1994). Marital functioning and the anxiety disorders. Behavior Therapy, 25, 407-429.

Emmelkamp, P., van der Helm, M., MacGillavry, D., \& van Zanten, B. (1984). Marital therapy with clinically distressed couples: A comparative evaluation of system-theoretic, contingency contracting, and communication skills approaches. In K. Hahlweg \& N. S. Jacobson (Eds.), Marital interaction: Analysis and modification (pp. 36-52). New York: Guilford Press.

Emmelkamp, P. M. G., Van Dyck, R., Bitter, M., Heins, R., Onstein, E. J., \& Eisen, B. (1992). Spouse-aided therapy with agoraphobics. British Journal of Psychiatry, 160, 51-56.

Emmelkamp, P. M. G., van Linden van den Heuvell, C., Ruphan, M., Sanderman, R., Scholing, A., \& Stroink, F. (1988). Cognitive and behavioral interventions: A comparative evaluation with clinically distressed couples. Journal of Family Psychology, 1, 365-377.

Epstein, N., \& Eidelson, R. J. (1981). Unrealistic beliefs of clinical couples: Their relationship to expectations, goals and satisfaction. American Journal of Family Therapy, 9(4), 13-22.
Ersner-Hershfield, R., \& Kopel, S. (1979). Group treatment of preorgasmic women. Journal of Consulting and Clinical Psychology, 47, $750-759$.

Everaerd, W., \& Dekker, J. (1981). A comparison of sex therapy and communication therapy: Couples complaining of orgasmic dysfunction. Journal of Sex and Marital Therapy, 7, 278-289.

Everaerd, W., \& Dekker, J. (1985). Treatment of male sexual dysfunction: Sex therapy compared with systernatic desensitization and rational emotive therapy. Behaviour Research and Therapy, 23, 13-25.

Ewart, C. K. (1978, August). Behavior contracts in couple therapy: An experimental evaluation of quid pro quo and good faith models. Paper presented at the annual meeting of the Association for Advancement of Behavior Therapy, Toronto, Ontario, Canada.

Falloon, I. R. H., Boyd, J. L., \& McGill, C. W. (1984). Family care of schizophrenia: A problem-solving approach to the treatment of mental illness. New York: Guilford Press.

Falloon, I. R. H., Boyd, J. L., McGill, C. W., Williamson, M., Razani, J., Moss, H. B., Gilderman, A. M., \& Simpson, G. M. (1985). Family management in the prevention of morbidity of schizophrenia: Clinical outcome of a two year longitudinal study. Archives of General Psychiatry, 42, 887-896.

Falloon, I. R. H., McGill, C. W., Boyd, J. L., \& Pederson, J. (1987). Family management in the prevention of morbidity of schizophrenia: Social outcome of a two-year longitudinal study. Psychological Medicine, 17, 59-66.

Foley, S. H., Rounsaville, B. J., Weissman, M. M., Sholomskas, D., \& Chevron, E. (1989). Individual versus conjoint interpersonal therapy for depressed patients with marital disputes. International Journal of Family Psychiatry, 10, 29-42.

Fuller, R. K., Branchey, L., Brightwell, D. R., Derman, R. M., Emrick, C. C., Iber, F. K., James, K. E., Lacoursiere, R. B., Lee, K. K., Lowensteam, I., Maany, I., Neiderhiser, D., Nocks, J. J., \& Shaw, S. (1986). Disulfiram treatment of alcoholism: A Veterans Administration cooperative study. Journal of the American Medical Association, 256, 1449-1455.

Girodo, M., Stein, S. J., \& Dotzenroth, S. E. (1980). The effects of communication skills training and contracting on marital relations. Behavioral Engineering, 6, 61-76.

Glick, I., Clarkin, J., Spencer, J., Haas, G., Lewis, A., Peyser, J., DeMane, N., Good-Ellis, M., Harris, E., \& Lestelle, V. (1985). A controlled evaluation of inpatient family intervention: 1 . Preliminary results of a 6-month follow-up. Archives of General Psychiatry, 42, 882-886.

Glynn, S. M. (1993). Family-based treatment for major mental illness: A new role for psychologists. California Psychologist, 25, 22-23.

Glynn, S., Pugh, R., \& Rose, G. (1993). Benefits of attendance at a state hospital family education workshop. Psychosocial Rehabilitation Journal, 16, 95-101.

Goldman, H. H. (1984). The chronically mentally ill: Who are they? Where are they? In M. Mirabi (Ed.), The chronically ill: Research and services (pp. 33-44). New York: Spectrum.

Goldstein, M., Rodnick, E., Evans, J., May, P., \& Steinberg, M. (1978). Drug and family therapy in the aftercare of acute schizophrenics. Archives of General Psychiatry, 35, 1169-1177.

Gotlib, I. H., \& Beach, S. R. H. ( 1995). A marital/family discord model of depression: Implications of therapeutic intervention. In N. S. Jacobson \& A.S. Gurman (Eds.), Clinical handbook of couple therapy (pp. 411-436). New York: Guilford Press.

Greenberg, L. S., \& Johnson, S. M. (1988). Emotionally focused therapy for couples. New York: Guilford Press.

Hahlweg, K., \& Markman, H. J. (1988). Effectiveness of behavioral marital therapy: Empirical status of behavioral techniques in preventing and alleviating marital distress. Joumal of Consulting and Clinical Psychology, 56, 440-447.

Hahlweg, K., Revenstorf, D., \& Schindler, L. (1982). Treatment of marital distress: Comparing formats and modalities. Advances in Behavior Research and Therapy, 4, 57-74. 
Hahlweg, K., Schindler, L., Revenstorf, D., \& Brengelmann, J. C. (1984). The Munich marital therapy study. In K. Hahlweg \& N.S. Jacobson (Eds.), Marital interaction: Analysis and modification (pp. 3-26). New York: Guilford Press.

Halford, K. W., Sanders, M. R., \& Behrens, B. C. (1993). A comparison of the generalization of behavioral marital therapy and enhanced behavioral marital therapy. Journal of Consulting and Clinical Psychology, 61, 51-60.

Hand, I., Angenendt, J.; Fischer, M., \& Wilke, C. (1986). Exposure invivo with panic management for agoraphobia: Treatment rationale and long-term outcome. In I. Hand \& H.-U. Wittchen (Eds.), Panic and phobias: Empirical evidence of theoretical models and long-term effects of behavioral treatments (pp. 104-127). Berlin: Springer-Verlag.

Hartman, L. M., \& Daly, E. M. (1983). Relationship factors in the treatment of sexual dysfunction. Behaviour Research and Therapy. 2I, 153-160.

Hatfield, A. B. (1990), Family education in mental illness. New York: Guilford Press.

Hawton, K. (1995). Treatment of sexual dysfunctions by sex therapy and other approaches. British Journal of Psychiatry, 17, 307-314.

Hawton, K., \& Catalan, J. (1986). Prognostic factors in sex therapy. Behaviour Research and Therapy, 24, 377-385.

Hawton, K., Catalan, J., \& Fagg, J. (1991). Low sexual desire: Sex therapy results and prognostic factors. Behaviour Research and Therapy, 29, 217-224.

Hawton, K., Catalan, J., \& Fagg, J. (1992). Sex therapy for erectile dysfunction: Characteristics of couples, treatment outcome, and prognostic factors. Archives of Sexual Behavior, 21, 161-175.

Heather, N., \& Tebbutt, J. (1989). Definitions of non-abstinent and abstinent categories in alcoholism treatment outcome classifications: A review and proposal, Drug and Alcohol Dependence, 24, 83-93.

Heiman, J. R., \& LoPiccolo, J. (1983). Clinical outcome of sex therapy: Effectiveness of daily vs. weekly treatment. Archives of General Psychiatry, 40, 443-449.

Himadi, W. G., Cerny, J. A., Barlow, D. H., Cohen, S., \& O'Brien, G. T. (1986). The relationship of marital adjustment to agoraphobic treatment outcome. Behaviour Research and Therapy, 24, 321-332.

Hogarty, G. E., Anderson, C., Reiss, D., Kornblith, S., Greenwald, D., Ulrich, R., \& Carter, M. (1991 ). Family psychoeducation, social skills training, and maintenance chemotherapy in the aftercare treatment of schizophrenia: II. Two year effects of a controlled study on relapse and adjustment. Archives of General Psychiatry, 48, 340-347.

Huber, C. H., \& Milstein, B. (1985). Cognitive restructuring and a collaborative set in couples' work. American Joumal of Family Therapy, 13(2), 17-27.

Hunt, G. M., \& Azrin, N. H. (1973). A community-reinforcement approach to alcoholism. Behaviour Research and Therapy, 11, 91-104.

Hurlbert, D. F. (1993). A comparative study using orgasm consistency training in the treatment of women reporting hypoactive sexual desire. Journal of Sex and Marital Therapy, 19, 41-55.

Hurlbert, D. F., White, L. C., Powell, R. D., \& Apt, C. (1993). Orgasm consistency training in the treatment of women reporting hypoactive sexual desire: An outcome comparison of women-only groups and couples-only groups. Journal of Behavior Therapy and Experimental Psychiatry, 24, 3-13.

Jacob, T., \& Leonard, K. (1988). Alcoholic-spouse interaction as a function of alcoholism subtype and alcohol consumption interaction. Journal of Abnormal Psychology, 97, 231-237.

Jacobson, N. S. (1977). Problem-solving and contingency contracting in the treatment of marital discord. Joumal of Consulting and Clinical Psychology, 45, 92-100.

Jacobson, N. S. (1978). Specific and nonspecific factors in the effectiveness of a behavioral approach to the treatment of marital discord. Journal of Consulting and Clinical Psychology, 46, 442-452.

Jacobson, N. S. (1984). A component analysis of behavioral marital therapy: The relative effectiveness of behavioral exchange and commu- nication/problem-solving training. Journal of Consulting and Clinical Psychology, 52, 295-305.

Jacobson, N. S., \& Addis, M. E. (1993). Research on couples and couple therapy: What do we know? Journal of Consulting and Clinical Psychology, 61, 85-93.

Jacobson, N. S., \& Christensen, A. (1996). Integrative couple therapy. New York: Norton.

Jacobson, N. S., Dobson, K., Fruzzetti, A. E., Schmaling, D. B., \& Salusky, S. (1991). Marital therapy as a treatment for depression. Journal of Consulting and Clinical Psychology, 59, 547-557.

Jacobson, N. S., Follette, W. C., \& Pagel, M. (1986). Predicting who will benefit from behavioral marital therapy. Journal of Consulting and Clinical Psychology, 54, 518-522.

Jacobson, N. S., Follette, W. C., \& Revenstorf, D. (1984). Psychotherapy outcome research: Methods for reporting variability and evaluating clinical significance. Behavior Therapy, 15, 336-352.

Jacobson, N. S., Follette, W. C., Revenstorf, D., Baucom, D. H., Hahlweg, K., \& Margolin, G. (1984). Variability in outcome and clinical significance of behavioral marital therapy: A reanalysis of outcome data. Journal of Consulting and Clinical Psychology, 52, 497-504.

Jacobson, N. S., Fruzzetti, A. E., Dobson, K., Whisman, M., \& Hops, H. (1993). Couple therapy as a treatment for depression II: The effects of relationship quality and therapy on depressive relapse. Journal of Consulting and Clinical Psychology, 61, 516-519.

Jacobson, N. S., \& Margolin, G. (1979). Marital therapy: Strategies based on social learning and behavior exchange principles. New York: Brunner/Mazel.

Jacobson, N. S., Schmaling, K. B., \& Holtzworth-Munroe, A. (1987), Component analysis of behavioral marital therapy: 2-year follow-up and prediction of relapse. Journal of Marital and Family Therapy, 13, 187-195.

James, P. S. (1991). Effects of a communication training component added to an emotionally focused couples therapy. Journal of Marital and Family Therapy, 17, 263-275.

Jannoun, L., Munby, M., Catalan, J., \& Gelder, M. (1980). A homebased program for agoraphobia. Replication and controlled evaluation. Behavior Therapy, 11, 294-305.

Johnson, S. M., \& Greenberg, L. S. (1985). Differential effects of experiential and problem-solving interventions in resolving marital conflict. Journal of Consulting and Clinical Psychology, 53, 175-184.

Johnson, S. M., \& Greenberg, L. S. (Eds.). (1994). The heart of the matter: Emotion in marital therapy. New York: Brunner/Mazel.

Johnson, S. M., \& Greenberg, L. S. (1995). The emotionally focused approach to problems in adult attachment. In N. S. Jacobson \& A. S. Gurman (Eds.), Clinical handbook of couple therapy (pp. 121-141). New York: Guilford Press.

Kantor, G. K., \& Straus, M. A. (1990). The "drunken bum" theory of wife beating. In M. A. Straus \& R. J. Gelles (Eds.), Physical violence in American families (pp. 203-224). New Brunswick, NJ: Transaction.

Kendall, P. C., \& Grove, W. (1988). Normative comparisons in therapy outcome. Behavioral Assessment, 10, 147-158.

Köttgen, C., Sönnichsen, I., Mollenhauer, K., \& Jurth, R. (1984). Group therapy with the families of schizophrenic patients: Results of the Hamburg Camberwell-Family Interview Study II. International Journal of Family Psychiatry, 5, 84-94.

Kuipers, L., Leff, J., \& Lam, D. (1992). Family work for schizophrenia: A practical guide. London: Gaskell.

Lam, D. H. (1991). Psychosocial family intervention in schizophrenia: A review of empirical studies. Psychological Medicine, 21, 423-441.

Lebow, J. L., \& Gurman, A. S. (1995). Research assessing couple and family therapy. In J. T. Spence, J. M. Darley, \& D. J. Foss (Eds.), Annual review of psychology (Vol. 46, pp. 27-57). Palo Alto, CA: Annual Reviews.

Leff, J. P., Berkowitz, R., Shavit, N., Strachan, A., Glass, I., \& Vaughn, C. (1990). A trial of family therapy versus a relatives' group for 
schizophrenia. Two-year follow-up. British Journal of Psychiatry, 157, 571-577.

Leff, J., \& Vaughn, C. (1985). Expressed emotion in families: Its significance for mental illness. New York: Guilford Press.

Leff, J., Kuipers, L., Berkowitz, R., \& Sturgeon, D. (1985). A controlled trial of social intervention in the families of schizophrenic patients: Two year follow-up. British Journal of Psychiatry, 146, 594-600.

Leiblum, S. R., \& Ersner-Hershfield, R. (1977). Sexual enhancement group for dysfunctional women: An evaluation. Journal of Sex and Marital Therapy, 3, 139-151.

Leonard, K. E., \& Jacob, T. (1988). Alcohol, alcoholism and family violence. In V. B. VanHasselt, R. L. Morrison, A. S. Bellack, \& M. Hersen (Eds.), Handbook of family violence (pp. 383-406). New York: Plenum.

Liberman, R., Levine, J., Wheeler, E., Sanders, N., \& Wallace, C. J. (1976). Marital therapy in groups: A comparative evaluation of behavioral and interaction formats. Acta Psychiatrica Scandinavica, 266, $1-34$.

Linszen, D., Dingemans, P., Van der Does, J. W., Nugter, A., Scholte, P., Lenior, R., \& Goldstein, M. J. (1996). Treatment, expressed emotion and relapse in recent onset schizophrenic disorders. Psychological Medicine, 26, 333-342.

Longabaugh, R., Beattie, M., Noel, N., Stout, R., \& Malloy, P. (1993). The effect of social investment on treatment outcome. Journal of Studies on Alcohol, 54, 465-478.

LoPiccolo, J., Heiman, J. R., Hogan, D. R., \& Roberts, C. W. (1985). Effectiveness of single therapists versus cotherapy teams in sex therapy. Journal of Consulting and Clinical Psychology, 53, 287-294.

LoPiccolo, J., \& Lobitz, W. C. (1972). The role of masturbation in the treatment of orgasmic dysfunction. Archives of Sexual Behavior, 2, $163-171$.

LoPiccolo, J., \& Steger, J. C. (1974). The Sexual Interaction Inventory: A new instrument for assessment of sexual dysfunction. Archives of Sexual Behavior, 3, 585-595.

LoPiccolo, J., \& Stock, W. E. (1986). Treatment of sexual dysfunction. Journal of Consulting and Clinical Psychology, 54, 158-167.

MacFee, D. C., \& Johnson, S. M. (1995). Low sexual desire in women: The effects of marital therapy. Journal of Sex and Marital Therapy, $21,159-182$.

Marlatt, G. A., \& Gordon, J. R. (Eds.). (1985). Relapse prevention: Maintenance strategies in the treatment of addictive behavior. New York: Guilford Press.

Masters, W. H., \& Johnson, V. E. (1970). Human sexual inadequacy. Boston: Little, Brown.

Mathews, A., Bancroft, J., Whitehead, A., Hackmann, A., Julier, D., Bancroft, J., Gath, D., \& Shaw, P. (1976). The behavioural treatment of sexual inadequacy: A comparative study. Behaviour Research and Therapy, 14, 427-436.

Mathews, A., Whitehead, A., \& Kellet, J. (1983). Psychological and hormonal factors in the treatment of female sexual dysfunction. Psychological Medicine, 13, 83-92.

Mathews, A. M., Gelder, M. G., \& Johnston, D. W. (1981). Agoraphobia: Nature and treatment. New York; Guilford Press.

Mathews, A. M., Teasdale, J., Munby, M., Johnston, D., \& Shaw, P. (1977). A home-based treatment program for agoraphobia. Behavior Therapy, 8, 915-924.

McCrady, B. S., \& Epstein, E. E. (1995). Directions for research on alcoholic relationships: Marital- and individual-based models of heterogeneity. Psychology of Addictive Behaviors, 9, 157-166.

McCrady, B. S., Noel, N.E., Abrams, D. B., Stout, R. L., Nelson, H. F., \& Hay, W. M. (1986). Comparative effectiveness of three types of spouse involvement in outpatient behavioral alcoholism treatment. Journal of Studies on Alcohol, 47, 459-467.

McCrady, B. S., Stout, R., Noel, N., Abrams, D., \& Nelson, H. F. (1991). Effectiveness of three types of spouse-involved behavioral alcoholism treatment. British Journal of Addiction, 86, 1415-1424.
McFarlane, W. R. (1990). Multiple family groups and the treatment of schizophrenia. In M. I. Herz, S. J. Keith, \& J. P. Docherty (Eds.), Handbook of schizophrenia. Vol. 4: Psychosocial treatment of schizophrenia (pp. 167-189). Amsterdam: Elsevier.

McFarlane, W. R., Link, B., Dushay, R., Marchal, J., \& Crilly, J. (1995). Psychoeducational multiple family groups: Four-year relapse outcome in schizophrenia. Family Process, 34, 127-144.

McFarlane, W. R., Lukens, E., Link, B., Dushay, R., Deakins, S. A., Newmark, M., Dunne, E. J., Horen, B., \& Toran, J. (1995). Multiplefamily groups and psychoeducation in the treatment of schizophrenia. Archives of General Psychiatry, 52, 679-687.

Mehta, M. (1990). A comparative study of family-based and patientbased behavioral management in obsessive-compulsive disorder. British Journal of Psychiatry, 157, 133-135.

Miller, W. R. (1992). Client/treatment matching in addictive behavior. Behavior Therapist, 15, 7-8.

Miller, W. R., Brown, J. M., Simpson, T. L., Handmaker, N. S., Bien, T. H., Luckie, L. F., Montogomery, H. A., Hester, R. K., \& Tonigan, J. S. (1995). What works? A methodological analysis of the alcohol treatment outcome literature. In R. K. Hester \& W. R. Miller (Eds.), Handbook of alcoholism treatment approaches: Effective alternatives (pp. 12-44). Boston: Allyn \& Bacon.

Mills, P. D., \& Hansen, J. C. (1991). Short-term group interventions for mentally ill young adults living in a community residence and their families. Hospital and Community Psychiatry, 42, 1144-1149.

Moos, R. H., Finney, J. W., \& Gamble, W. (1982). The process of recovery from alcoholism: Comparing spouses of alcoholic patients and matched community controls. Journal of Studies on Alcohol, 43, 888-909.

Mueser, K. T. (1996). Helping families manage severe mental illness. Psychiatric Rehabilitation Skills, 1, 21-42.

Mueser, K. T., \& Berenbaum, H. (1990). Psychodynamic treatment of schizophrenia: Is there a future? Psychological Medicine, 20, 253262.

Mueser, K. T., \& Glynn, S. M. (1995). Behavioral family therapy for psychiatric disorders. Boston: Allyn \& Bacon.

Mueser, K. T., \& Glynn, S. M. (in press). Family intervention for schizophrenia. In K. S. Dobson \& K. D. Craig (Eds.), Best practice: Developing and promoting empirically supported interventions. Newbury Park, CA: Sage.

Mueser, K. T., Yarnold, P. R., Levinson, D. F., Singh, H., Bellack, A. S., Kee, K., Morrison, R. L., \& Yadalam, K. G. (1990). Prevalence of substance abuse in schizophrenia: Demographic and clinical correlates. Schizophrenia Bulletin, 16, 31-56.

Noel, N. E., McCrady, B. S., Stout, R. L., \& Fisher-Nelson, H. (1987). Predictors of attrition from an outpatient alcoholism treatment program for couples. Journal of Studies on Alcohol, 48, 229-234.

Nuechterlein, K. W., \& Dawson, M. E. (1984). A heuristic vulnerability/stress model of schizophrenic episodes. Schizophrenia Bulletin, 10, 300-312.

Oatley, K., \& Hodgson, D. (1987). Influence of husbands on the outcome of their agoraphobic wives' therapy. British Journal of Psychiatry, 150, 380-386.

O'Farrell, T. J. (Ed.). (1993). A behavioral marital therapy couples' group program for alcoholics and their spouses. Treating alcohol problems: Marital and family interventions (pp. 170-209). New York: Guilford Press.

O'Farrell, T. J., Choquette, K. A., Cutter, H. S. G., Brown, E. D., Bayog, R., McCourt, W., Lowe, J., Chan, A., \& Deneault, P. (1996). Costbenefit and cost-effectiveness analyses of behavioral marital therapy with and without relapse prevention sessions for alcoholics and their spouses. Behavior Therapy, 27, 7-24.

O'Farrell, T. J., Choquette, K. A., Cutter, H. S. G., Brown, E. D., \& McCourt, W. F. (1993). Behavioral marital therapy with and without additional couples relapse prevention sessions for alcoholics and their wives. Journal of Studies on Alcohol, 54, 652-666. 
O'Farrell, T. J., Cutter, H. S. G., \& Floyd, F. J. (1985). Evaluating behavioral marital therapy for male alcoholics: Effects on marital adjustment and communication from before to after treatment. Behavior Therapy, 16, 147-167.

O'Farrell, T. J., \& Murphy, C. M. (1995). Marital violence before and after alcoholism treatment. Journal of Consulting and Clinical Psychology, 63, 256-262.

O'Leary, K. D., \& Beach, S. R. H. (1990). Marital therapy: A viable treatment for depression and marital discord. American Journal of Psychiatry, 147, 183-186.

O'Leary, K. D., Riso, L. P., \& Beach, S. R. H. (1990). Attributions about the marital discord/depression link and therapy outcome. Behavior Therapy, 21, 413-422.

Penn, D. L., \& Mueser, K. T. (1996). Research update on the psychosocial treatment of schizophrenia. American Journal of Psychiatry, 153, 607-617.

Prince, S. E., \& Jacobson, N. S. (1995). A review and evaluation of marital and family therapies for affective disorders. Joumal of Marital and Family Therapy, 21, 377-401.

Project MATCH Research Group. (1997). Matching alcoholism treatments to client heterogeneity: Project MATCH posttreatment drinking outcome. Joumal of Studies on Alcohol, 58, 7-29.

Randolph, E. T., Glynn, S. M., Eth, S., Paz, G. G., Leong, G. B., \& Shaner, A. L. (1995, May). Family therapy for schizophrenia: Two year outcome. Paper presented at the annual meeting of the American Psychiatric Association, Miami, FL.

Regier, D. A., Farmer, M. E., Rae, D. S., Locke, B. Z., Keith, S. J., Judd, L. L., \& Goodwin, F. K. (1990). Comorbidity of mental disorders with alcohol and other drug abuse. Journal of the American Medical Association, 264, 2511-2518.

Riley, A. J., \& Riley, E. J. (1978). A controlled study to evaluate directed masturbation in the management of primary orgasmic failure in women. British Journal of Psychiatry, 135, 404-409.

Rosen, R. C., \& Leiblum, S. R. (1995). Treatment of sexual disorders in the 1990s: An integrated approach. Journal of Consulting and Clinical Psychology, 63, 877-890.

Rust, J. J., Golombok, S., \& Collier, J. (1988). Marital problems and sexual dysfunction: How are they related? British Journal of Psychiatry, 152, 629-631.

Schneidman, B., \& McGuire, L. (1976). Group therapy for nonorgasmic women: Two age levels. Archives of Sexual Behavior, 5, 239-248.

Schooler, N. R., Keith, S. J., Severe, J. B., Matthews, S. M., Bellack, A. S., Glick, I. D., Hargreaves, W. A., Kane, J. M., Ninan, P. T., Frances, A., Jacobs, M., Lieberman, J. A., Mance, R., Simpson, G. M., \& Woerner, M. G. (1997). Relapse and rehospitalization during maintenance treatment of schizophrenia: The effects of dose reduction and family treatment. Archives of General Psychiatry, 54, 453-463.

Segraves, K. B., \& Segraves, R. T. (1991). Hypoactive sexual desire disorder: Prevalence and comorbidity in 909 subjects. Journal of Sex and Marital Therapy, 17, 55-58.

Shadish, W. R., Montomery, L. M., Wilson, P., Wilson, M. R., Bright, I., \& Okwumabua, T. (1993). Effects of family and marital psychotherapies: A meta-analysis. Journal of Consulting and Clinical Psychology, 61, 992-1002.

Shoham, V., \& Rohrbaugh, M. (1995). Client-therapy interaction research: Widening the lens and sharpening the questions. In M. Aveline \& D. Shapiro (Eds.), Research foundations for psychotherapy research (pp. 73-95). Sussex, England: Wiley.

Shoham-Salomon, V., \& Hanna, M. T. (1991). Client-treatment interactions in the study of differential change processes. Journal of Consulting and Clinical Psychology, 59, 217-225.

Sidley, G. L., Smith, J., \& Howells, K. (1991). Is it ever too late to learn? Information provision to relatives of long-term schizophrenia sufferers. Behavioural Psychotherapy, 19, 305-320.

Sisson, R. W., \& Azrin, N. H. (1986). Family-member involvement to initiate and promote treatment of problem drinkers. Journal of Behavior Therapy and Experimental Psychiatry, 17, 15-21.

Smith, J., \& Birchwood, M. (1987). Specific and non-specific effect of educational interventions with families of schizophrenic patients. British Journal of Psychiatry, 150, 645-652.

Snow, R. E. (1991). Aptitude-treatment interaction as a framework for research on individual differences in psychotherapy. Journal of Consulting and Clinical Psychology, 59, 205-216.

Snyder, D. K., \& Wills, R. M. (1989). Behavioral versus insight-oriented marital therapy: Effects on individual and interspousal functioning. Journal of Consulting and Clinical Psychology, 57, 39-46.

Snyder, D. K., Wills, R. M., \& Grady-Fletcher, A. (1991). Long-term effectiveness of behavioral versus insight-oriented marital therapy: A 4-year follow-up study. Journal of Consulting and Clinical Psychology, 59, 138-141.

Solomon, P., Draine, J., Mannion, E., \& Meisel, M. (1996a). Impact of brief family psychoeducation on self-efficacy. Schizophrenia Bulletin, 22, 41-50.

Solomon, P., Draine, J., Mannion, E., \& Meisel, M. (1996b). The impact of individualized consultation and group workshop family education interventions on ill relative outcomes. Journal of Nervous and Mental Disease, 184, 252-255.

Stuart, F., Hammond, D., \& Pett, M. (1987). Inhibited sexual desire in women. Archives of Sexual Behavior, 16, 91-106.

Stuart, R. B. (1980). Helping couples change: A social learning approach to marital therapy. New York: Guilford Press.

Tarrier, N., Barrowclough, C., Porceddu, K., \& Fitzpatrick, E. (in press). The Salford Family Intervention Project for schizophrenic relapse prevention: Five and eight year accumulating relapses. British Joumal of Psychiatry.

Tarrier, N., Barrowclough, C., Vaughn, C., Bamrah, J., Porceddu, K., Watts, S., \& Freeman, H. (1989). Community management of schizophrenia: A two-year follow-up of a behavioral intervention with families. British Journal of Psychiatry, 154, 625-628.

Tarrier, N., Lowson, K., \& Barrowclough, C. (1991). Some aspects of family interventions in schizophrenia: II. Financial considerations. British Journal of Psychiatry, 159, 481 - 484.

Telles, C., Karno, M., Mintz, J., Paz, G., Arias, M., Tucker, D., \& Lopez, S. (1995). Immigrant families coping with schizophrenia: Behavioral family intervention versus case management with a low-income Spanish-speaking population. British Journal of Psychiatry, 167, 473-479.

Tiefer, L. (1994). Three crises facing sexology. Archives of Sexual Behavior, 23, 361-374.

Tsoi-Hoshmand, L. (1976). Marital therapy: An integrated behaviorallearning approach. Journal of Marriage and Family Counseling, 2, $179-191$.

Turkewitz, H., \& O'Leary, K. D. (1981). A comparative outcome study of behavioral marital therapy and communication therapy. Journal of Marital and Family Therapy, 7, 159-169.

Vaughn, K., Doyle, M., McConaghy, N., Blaszczynski, A., Fox, A., \& Tarrier, N. (1992). The Sydney Intervention Trial: A controlled trial of relatives' counseling to reduce schizophrenic relapse. Social Psychiatry and Psychiatric Epidemiology, 27, 16-21.

Walker, J. G., Johnson, S., Manion, I., \& Cloutier, P. (1996). Emotionally focused marital intervention for couples with chronically ill children. Journal of Consulting and Clinical Psychology, 64, 1029-1036.

Whitehead, A., \& Mathews, A. (1986). Factors related to successful outcome in the treatment of sexually unresponsive women. Psycholog ical Medicine, 16, 373-378.

Wierzbicki, M., \& Pekarik, G. (1993). A meta-analysis of psychotherapy dropout. Professional Psychology: Research and Practice, 24, 190195.

Wilson, G. L., Bornstein, P. H., \& Wilson, L. J. (1988). Treatment of relationship dysfunction: An empirical evaluation of group and conjoint behavioral marital therapy. Joumal of Consulting and Clinical Psychology, 56, 929-931. 
Xiong, W., Phillips, M. R., Hu, X., Ruiwen, W., Dai, Q., Kleinman, J., \& Kleinman, A. (1994). Family-based intervention for schizophrenic patients in China: A randomized controlled trial. British Journal of Psychiatry, 165, 239-247.

Zastowny, T. R., Lehman, A. F., Cole, R. E., \& Kane, C. (1992). Family management of schizophrenia: A comparison of behavioral and supportive family treatment. Psychiatric Quarterly, 63, 159-186.

Zhang, M., Wang, M., Li, J., \& Phillips, M. R. (1994). Randomizedcontrol trial of family intervention for 78 first-episode male schizophrenic patients: An 18-month study in Suzhou, Jiangsu. British Journal of Psychiatry. 165, 96-102.

Zhang, M., Yan, H., Yao, C., Ye, J., Yu, Q., Chen, P., Guo, L., Yang, J.,
Qu, G., Zhen, W., Cai, J., Shen, M., Hou, J., Wang, L., Zhang, Y., Zhang, B., Orley, J., \& Gittelman, M. (1993). Effectiveness of psychoeducation of relatives of schizophrenic patients: A prospective cohort study in five cities of China. International Joumal of Mental Health, 22, 47-59.

Zimmer, D. (1987). Does marital therapy enhance the effectiveness of treatment for sexual dysfunction? Joumal of Sex and Marital Therapy. 13, 193-209.

Zweben, A. (1986). Problem drinking and marital adjustment. Journal of Studies on Alcohol, 47, 167-172.

Received January 20, 1997 Accepted July 22, 1997

\section{American Psychological Association SUBSCRIPTION Claims INFORMATION}

Today's Date:

We provide this form to assist members, institutions, and nonmember individuals with any subscription problems. With the appropriate information we can begin a resolution. If you use the services of an agent, please do NOT duplicate claims through them and directly to us. PLEASE PRINT CLEARLY AND IN INK IF POSSIBLE.

PRINT FULL NAME OR KEY NAME OF INSTITUTION

\begin{tabular}{lll}
\hline ADDRESS & & \\
\hline & & \\
\hline CTTY & STATECOUNTRY & ZIP
\end{tabular}

YOUR NAME AND PHONE NUMBER

TITLE

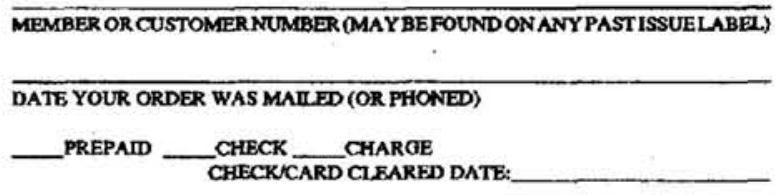

(If possible, sead a copy, front and back, of your cancolled check to help us in our research of your claim.)

ISSUES:

NUMBER OR MONTH

Thank you. Once a claim is received and resolved, delivery of replacement issues routinely takes 4-6 weeks.

(TO BE FILLED OUT BY APA STAFF)

DATE RECEIVED:

DATE OF ACTION:

ACTION TAKEN:

INV. NO. \& DATE:

STAFF NAME:

LABEL NO. \& DATE:

Send this form to APA Subscription Claims, 750 First Street, NE, Washington, DC 20002-4242

PLEASE DO NOT REMOVE. A PHOTOCOPY MAY BE USED. 